\title{
Investigation of particle and vapor wall-loss effects on controlled wood-smoke smog-chamber experiments
}

\author{
Q. Bian ${ }^{1}$, A. A. May $^{2}$, S. M. Kreidenweis ${ }^{1}$, and J. R. Pierce ${ }^{1,3}$ \\ ${ }^{1}$ Department of Atmospheric Science, Colorado State University, Fort Collins, CO, USA \\ ${ }^{2}$ Department of Civil, Environmental and Geodetic Engineering, the Ohio State University, Columbus, OH, USA \\ ${ }^{3}$ Department of Physics and Atmospheric Science, Dalhousie University, Halifax, NS, Canada \\ Correspondence to: S. M. Kreidenweis (sonia@atmos.colostate.edu) and J. R. Pierce (jeffrey.pierce@ colostate.edu)
}

Received: 7 May 2015 - Published in Atmos. Chem. Phys. Discuss.: 5 June 2015

Revised: 4 September 2015 - Accepted: 25 September 2015 - Published: 6 October 2015

\begin{abstract}
Smog chambers are extensively used to study processes that drive gas and particle evolution in the atmosphere. A limitation of these experiments is that particles and gas-phase species may be lost to chamber walls on shorter timescales than the timescales of the atmospheric processes being studied in the chamber experiments. These particle and vapor wall losses have been investigated in recent studies of secondary organic aerosol (SOA) formation, but they have not been systematically investigated in experiments of primary emissions from combustion. The semi-volatile nature of combustion emissions (e.g. from wood smoke) may complicate the behavior of particle and vapor wall deposition in the chamber over the course of the experiments due to the competition between gas/particle and gas/wall partitioning. Losses of vapors to the walls may impact particle evaporation in these experiments, and potential precursors for SOA formation from combustion may be lost to the walls, causing underestimations of aerosol yields. Here, we conduct simulations to determine how particle and gas-phase wall losses contributed to the observed evolution of the aerosol during experiments in the third Fire Lab At Missoula Experiment (FLAME III). We use the TwO-Moment Aerosol Sectional (TOMAS) microphysics algorithm coupled with the organic volatility basis set (VBS) and wall-loss formulations to examine the predicted extent of particle and vapor wall losses. We limit the scope of our study to the dark periods in the chamber before photo-oxidation to simplify the aerosol system for this initial study.

Our model simulations suggest that over one-third of the initial particle-phase organic mass $(41 \%)$ was lost during the experiments, and over half of this particle-organic mass loss
\end{abstract}

was from direct particle wall loss ( $65 \%$ of the loss) with the remainder from evaporation of the particles driven by vapor losses to the walls (35\% of the loss). We perform a series of sensitivity tests to understand uncertainties in our simulations. Uncertainty in the initial wood-smoke volatility distribution contributes $18 \%$ uncertainty to the final particleorganic mass remaining in the chamber (relative to baseassumption simulation). We show that the total mass loss may depend on the effective saturation concentration of vapor with respect to the walls as these values currently vary widely in the literature. The details of smoke dilution during the filling of smog chambers may influence the mass loss to the walls, and a dilution of $\sim 25: 1$ during the experiments increased particle-organic mass loss by $33 \%$ compared to a simulation where we assume the particles and vapors are initially in equilibrium in the chamber. Finally, we discuss how our findings may influence interpretations of emission factors and SOA production in wood-smoke smog-chamber experiments.

\section{Introduction}

Wood burning, including agricultural combustion and wildfires in forests, grasses and woodlands, is the major primary source of atmospheric carbonaceous particles globally, comprising black carbon (BC) as well as organic carbon material in both the particle and vapor phases. Wood smoke is known to have important health (Naeher et al., 2007; Jassen, 2012; Johnston et al., 2012) and climate effects (Bond et al., 2013), yet the aerosol emission estimates for wood burning 
(mainly open burning) of $33800 \mathrm{Gg}^{-1} \mathrm{yr}^{-1}$ have an uncertainty ranging from a factor of 0.6-4 (Bond et al., 2013). The net effect of the climate forcing from biomass-burning aerosol has been estimated in some studies to be nearly zero or negative due to the dominant cooling direct effect of primary organic aerosol (POA) over the warming from BC, as well as an indirect cooling effect from the particles' interactions with clouds by modifying the cloud albedo (Bond et al., 2013). Others have argued that biomass burning may still cause a net global warming because warming effects (e.g. cloud absorption effects, semi-direct effects, and aerosol absorption) might exceed the cooling effects (Chung et al., 2012; Jacobson, 2014). Thus, the climate effects of biomassburning aerosol are highly uncertain. In radiative forcing estimates, the size, composition, and morphology of biomassburning particles are important parameters (Sakamoto et al., 2015; Giordano et al., 2015). In-plume coagulation, semivolatile POA evaporation, and condensation of low-volatility secondary organic vapor onto the pre-existing aerosols in the atmosphere generally govern the particle size evolution during the smoke transport (Jimenez et al., 2009; DeCarlo et al., 2010; Sakamoto et al., 2015). In addition, nucleation of particles has also been observed in both chamber and field studies of biomass burning during the photo-oxidation process (Rissler et al., 2006; Hennigan et al., 2012).

POA from wood smoke has been demonstrated to be semivolatile in recent experiments, and thus some POA will evaporate during dilution of a smoke plume (May et al., 2013b). Related experiments have shown that photo-oxidation of wood smoke in smog chambers may more than double the organic aerosol mass concentration, but in some experiments the total organic aerosol mass concentration had a net loss (Grieshop et al., 2009; Hennigan et al., 2011; Ortega et al., 2013; Platt et al., 2013). Estimates of secondary organic aerosol (SOA) formation from observations in ambient plumes also have mixed results, with some plumes showing little or no formation (Capes et al., 2009; Cubison et al., 2011; Akagi et al., 2012; May et al., 2015; Sakamoto et al., 2015) and some showing significant formation (Yokelson et al., 2009; DeCarlo et al., 2010; Vakkari et al., 2014), although different studies sampled the plumes during different stages of evolution, which may explain some of the discrepancies. Accurate simulation of wood-smoke particle mass evolution (i.e., POA and SOA) in chemical transport models is necessary to estimate the climate and health effects of wood-smoke emissions.

Photo-chemical oxidation of semi-volatile organic species (species that have non-trivial partitioning in both the particle and vapor phases) and intermediate-volatility organic species (species that are somewhat more volatile than semi-volatile species and primarily exist in the vapor phase) to lower volatility SOA is believed to be the major pathway of SOA formation during wood-smoke particle aging (Robinson et al., 2007; Grieshop et al., 2009; Huffman et al., 2009; Ortega et al., 2013; Jathar et al., 2014). As wood-smoke plumes dilute during transport, POA may evaporate from particles and SOA production enhanced by oxidation of these organic vapors. The volatility distribution of the biomass-burning vapor and particles may change correspondingly with increasing distance to the emission sources as POA evaporates and SOA forms.

Teflon smog chambers have been extensively used for emission and photo-chemistry studies. It has been known for decades that particle wall loss in these chambers may dominate the changes in the particle distribution under certain experimental conditions (Crump and Seinfeld, 1981; McMurry and Grosjean, 1985; McMurry and Rader, 1985). Particle wall losses are quantified and used to correct observed aerosol concentrations to deduce the SOA formation in smog-chamber studies (Weitkamp et al., 2007; Hennigan et al., 2011). In these studies, semi-volatile vapors are generally assumed to be in equilibrium with particles deposited to the walls, but not in equilibrium with the walls themselves. While vapor wall loss has also been explored for decades (e.g. McMurry and Grosjean, 1985), its magnitude has been relatively unconstrained (compared to particle-phase wall losses), and it is not accounted for in most smog-chamber studies. However, recent studies of vapor wall losses have shown that organic vapors have an absorptive partitioning behavior to the Teflon walls of the smog chambers, and that this absorption may be modeled using Henry's law (Loza et al., 2010; Matsunaga and Ziemann, 2010; Zhang et al., 2015). Zhang et al. (2014) showed that vapor wall losses may lead to underestimates of SOA formation from both biogenic and anthropogenic SOA precursor gases in some experiments by a factor of 4 for their experimental conditions.

In controlled wood-smoke smog-chamber experiments, particle and vapor wall losses may complicate the estimates of particle-phase mass loss and SOA production. Vapor wall loss can force vapor concentrations to be lower than their equilibrium concentrations with respect to the particle phase. This deviation from equilibrium will cause evaporation of semi-volatile POA and lead to particle-phase mass loss beyond direct losses of the particles to the walls. Furthermore, losses of semi-volatile and intermediate-volatility vapors to the walls will bias experimental SOA formation. Thus, both particle-phase and vapor-phase wall losses must be considered in wood-smoke smog-chamber experiments, yet to our knowledge, no such estimates are currently available.

The goal of this study, therefore, is to simulate the vapor and particle wall losses of wood-smoke POA that is introduced into a smog chamber, based on current knowledge of vapor and particle loss rates, to quantify their relative importance. For model initialization and validation, we use observations from the third Fire Lab At Missoula Experiments (FLAME III). We perform a series of sensitivity studies on unknown parameters to evaluate the model uncertainties and their effect on the predicted POA partitioning behavior. As our analysis of POA contains several dimensions of wallloss uncertainties, we limit the scope of this paper to POA 
Table 1. Data for 18 wood-smoke samples introduced to the smog chamber, including fuel types, initial number concentration measured by scanning mobility particle sizer (SMPS) and corresponding size distribution parameters (median diameter in nm and standard deviation, $\sigma)$, initial total aerosol non-refractory mass concentration as measured by the Aerodyne quadruple aerosol mass spectrometer (Q-AMS), the organic mass fraction in the aerosol phase, derived turbulence rate $\left(k_{\mathrm{e}}, \mathrm{s}^{-1}\right)$ and size-independent particle wall-loss coefficient $\left(k_{\mathrm{w}, \mathrm{p} 0}, \mathrm{~s}^{-1}\right)$ used in the Aerosol Parameters Estimation (APE) model. The Burn ID refers to the schedule of burns in FLAME III, as reported in Hennigan et al. (2011). The initial time is taken as the end of the chamber filling period, equivalent to the start of the 75 min mixing and characterization period, as described in the text.

\begin{tabular}{|c|c|c|c|c|c|c|c|c|c|}
\hline \multirow[t]{2}{*}{$\begin{array}{l}\text { Burn } \\
\text { ID }\end{array}$} & \multirow[t]{2}{*}{ Fuel type } & \multirow[t]{2}{*}{$\begin{array}{l}\text { Temp } \\
(\mathrm{K})\end{array}$} & \multirow{2}{*}{$\begin{array}{r}\text { Initial particle } \\
\text { number } \\
\text { concentration } \\
\left(\mathrm{cm}^{-3}\right)\end{array}$} & \multicolumn{2}{|c|}{ Num. size dist. } & \multirow{2}{*}{$\begin{array}{c}\text { Initial } \\
\text { total mass } \\
\text { concentration } \\
{ }^{1} \\
\left(\mu \mathrm{g} \mathrm{m}^{-3}\right)\end{array}$} & \multirow[t]{2}{*}{$\begin{array}{l}\text { Organic } \\
\text { mass } \\
\text { fraction }^{2}\end{array}$} & \multirow[t]{2}{*}{$\begin{array}{l}k_{\mathrm{w}, \mathrm{p} 0} \\
\left(\mathrm{~s}^{-1}\right)\end{array}$} & \multirow[t]{2}{*}{$\begin{array}{c}k_{\mathrm{e}} \\
\left(\mathrm{s}^{-1}\right)\end{array}$} \\
\hline & & & & $\begin{array}{r}\text { Median } \\
\text { diameter }(\mathrm{nm})\end{array}$ & $\begin{array}{r}\mathrm{SD} \\
\sigma\end{array}$ & & & & \\
\hline 37 & Lodgepole Pine & 292.9 & 5843 & 157 & 1.73 & 44.96 & 0.943 & $8.03 \times 10^{-5}$ & 1.07 \\
\hline 38 & Lodgepole Pine & 286.8 & 7612 & 127 & 1.67 & 40.96 & 0.896 & $6.27 \times 10^{-5}$ & 1.41 \\
\hline 40 & Ponderosa Pine & 279.5 & 6505 & 160 & 1.84 & 63.73 & 0.954 & $8.67 \times 10^{-5}$ & 0.69 \\
\hline 42 & Wire Grass & 277.0 & 8107 & 123 & 1.55 & 19.63 & 0.484 & $1.07 \times 10^{-4}$ & 0.77 \\
\hline 43 & Saw Grass & 284.2 & 5406 & 123 & 1.73 & 18.16 & 0.347 & $1.07 \times 10^{-4}$ & 0.52 \\
\hline 45 & Turkey Oak & 286.3 & 6334 & 106 & 1.63 & 16.80 & 0.506 & $8.11 \times 10^{-5}$ & 0.99 \\
\hline 47 & Gallberry & 286.7 & 8265 & 123 & 1.61 & 39.16 & 0.881 & $7.37 \times 10^{-5}$ & 0.19 \\
\hline 49 & Sage & 285.0 & 5486 & 127 & 1.71 & 17.76 & 0.321 & $8.84 \times 10^{-5}$ & 0.84 \\
\hline 51 & Alaskan Duff & 282.5 & 4175 & 88 & 1.83 & 20.38 & 0.898 & $7.00 \times 10^{-5}$ & 0.32 \\
\hline 53 & Sage & 287.2 & 5619 & 132 & 1.76 & 16.09 & 0.348 & $8.43 \times 10^{-5}$ & 0.91 \\
\hline 55 & White Spruce & 281.6 & 4641 & 115 & 1.83 & 27.73 & 0.761 & $8.13 \times 10^{-5}$ & 0.31 \\
\hline 57 & Ponderosa Pine & 277.9 & 6624 & 161 & 1.81 & 72.83 & 0.935 & $8.43 \times 10^{-5}$ & 0.96 \\
\hline 59 & Chamise & 281.9 & 7173 & 148 & 1.79 & 24.89 & 0.221 & $7.58 \times 10^{-5}$ & 0.83 \\
\hline 61 & Lodgepole Pine & 283.1 & 6059 & 153 & 1.79 & 63.03 & 0.944 & $6.30 \times 10^{-5}$ & 0.29 \\
\hline 63 & Pocosin & 277.9 & 7463 & 112 & 1.65 & 26.20 & 0.603 & $8.46 \times 10^{-5}$ & 0.37 \\
\hline 65 & Gallberry & 275.3 & 7763 & 159 & 1.68 & 85.98 & 0.899 & $1.43 \times 10^{-4}$ & 0.62 \\
\hline 66 & Black Spruce & 279.0 & 9828 & 96 & 1.66 & 35.21 & 0.852 & $1.02 \times 10^{-4}$ & 0.36 \\
\hline 67 & Wire Grass & 274.5 & 11580 & 129 & 1.52 & 36.51 & 0.619 & $5.78 \times 10^{-5}$ & 0.28 \\
\hline
\end{tabular}

${ }^{1}$ Total mass $=[\mathrm{OA}]+\left[\mathrm{SO}_{4}^{2-}\right]+\left[\mathrm{NO}_{3}^{-}\right]+\left[\mathrm{NH}_{4}^{+}\right]+[\mathrm{Cl}-]+[\mathrm{BC}] ;{ }^{2}$ Organic fraction $=[\mathrm{OA}] /\left([\mathrm{OA}]+\left[\mathrm{SO}_{4}^{2-}\right]+\left[\mathrm{NO}_{3}^{-}\right]+\left[\mathrm{NH}_{4}^{+}\right]+\left[\mathrm{Cl}^{-}\right]+[\mathrm{BC}]\right)$

and primary vapors, and we will investigate SOA-production uncertainties in a future paper. In Sect. 2, we describe the experimental procedure and model simulation. In Sect. 3, we present the results of the base simulation and sensitivity tests and discuss the potential influence of wall and vapor losses on SOA formation. Section 4 summarizes the results and gives recommendations for future work.

\section{Methods}

\subsection{Experimental description}

Smog-chamber experiments to investigate wood-smoke POA partitioning and wood-smoke SOA formation were carried out during the FLAME III study at the USDA/USFS Fire Sciences Laboratory (FSL) in Missoula, Montana during September-October 2009 (Hennigan et al., 2011; May et al., 2013b, 2014). Eighteen types of fuels were studied that represent North American vegetation that is typically burned in wild or prescribed fires. Fuel samples $(0.3-1.0 \mathrm{~kg})$ were arranged on a fuel bed in the FSL combustion chamber $\left(12.4 \mathrm{~m} \times 12.4 \mathrm{~m} \times 19.6 \mathrm{~m}, 3014 \mathrm{~m}^{3}\right.$, Table 1$)$, ignited electrically, and combusted in open burning. After burn completion and subsequent mixing of emissions in the FSL combustion chamber for $\sim 30 \mathrm{~min}$, a smoke sample was withdrawn and introduced to the Carnegie Mellon University (CMU) smog chamber, a Teflon bag with a volume of $\sim 7 \mathrm{~m}^{3}$, through a heated transfer line with an average $94 \%$ particle-transmission efficiency between 50 and $400 \mathrm{~nm}$ (Hennigan et al., 2011). Filling commenced until aerosol concentrations of $\sim 50 \mathrm{\mu g} \mathrm{m}^{-3}$ were achieved, representing $\sim 25 \mathrm{x}$ dilution from the conditions present in the FSL combustion chamber (dilution was a two-step process, including roughly 7:1 dilution in Dekati ejector dilutors and bag filling for the remainder; Hennigan et al., 2011). Sampling from the CMU smog chamber occurred through a thermodenuder (May et al., 2013a) that was upstream from an Aerodyne quadruple aerosol mass spectrometer (Q-AMS) and a scanning-mobility particle sizer (SMPS). Non-refractory speciated submicron aerosol mass $\left(\mathrm{OA}, \mathrm{SO}_{4}^{2-}, \mathrm{NO}_{3}^{-}, \mathrm{NH}_{4}^{+}\right.$, 
Table 2. Parameters used in the base-assumption simulations.

\begin{tabular}{|c|c|c|}
\hline Parameter & Definition & Value \\
\hline$\alpha_{\mathrm{p}}$ & Accommodation coefficient of vapor species on particle & 1 \\
\hline $\mathrm{A} / \mathrm{V}$ & $\begin{array}{l}\text { Surface-area-to-volume ratio of the chamber }\left(\mathrm{m}^{-1}\right) \text {, } \\
\text { assuming the bag chamber to be cubic }\end{array}$ & 3.14 \\
\hline$\alpha_{\mathrm{w}}$ & Accommodation coefficient of vapor species on the wall & $1.0 \times 10^{-5}$ \\
\hline$C_{i}^{*}$ & Saturation concentration range $\left(\mu \mathrm{g} \mathrm{m}^{-3}\right)$ & {$\left[10^{-3} 10^{-2} 10^{-1} 10^{0} 10^{1} 10^{2} 10^{3} 10^{4}\right]$} \\
\hline$\Delta H_{\mathrm{vap}, i}$ & Heat of vaporization $\left(\mathrm{kJ} \mathrm{mol}^{-1}\right)$ & $85-4 \times \log C_{i}^{* 1}$ \\
\hline$M_{i}$ & Species molecular weight $\left(\mathrm{g} \mathrm{mol}^{-1}\right)$ & $434-45 \times \log _{10} C_{i}^{* 2}$ \\
\hline$T$ & Temperature (K) & $\begin{array}{l}\text { Varied, according to the measurement } \\
\text { in each burn (Table 1) }\end{array}$ \\
\hline
\end{tabular}

\footnotetext{
${ }^{1}$ May et al. (2013b) and Robinson et al. (2007); the detailed values are shown in Table 3.
}

and $\mathrm{Cl}^{-}$) was characterized by the Q-AMS, black carbon (BC) was determined by a seven-channel Aethalometer at $880 \mathrm{~nm}$, and the number size distribution between diameters of 10.9 and $478.3 \mathrm{~nm}$ was measured by the SMPS. In this paper, we define the total submicron aerosol mass (TA) as the sum of $\mathrm{OA}, \mathrm{SO}_{4}^{2-}, \mathrm{NO}_{3}^{-}, \mathrm{NH}_{4}^{+}, \mathrm{Cl}^{-}$, and $\mathrm{BC}$, and we define the organic fraction (OF) as the ratio of OA / TA. To reconcile the volume and mass measurements between SMPS and aerosol mass spectrometer (AMS), we compute an effective density (DeCarlo et al., 2004) of the particles for each burn by dividing the total AMS mass by the total SMPS volume. For this purpose, the SMPS size distribution was extrapolated to $1 \mu \mathrm{m}$ (the upper size limit for the AMS), using a single lognormal fit of the SMPS volume distribution (Fig. S1 in the Supplement). While the volume distribution appears lognormal up to $400 \mathrm{~nm}$ (upper limit of the SMPS), we do not know for sure if the distribution follows the fit lognormal curve at larger sizes. Therefore, these calculated effective densities represent the combined effect of non-unity collection efficiencies in the AMS, particle density, and particle shape, but contain uncertainties due to the size extrapolation. We use the effective densities to translate modeled mass distributions to the measured values. Measurements of primary gas and particle concentrations were conducted for $\sim 75 \mathrm{~min}$ after smoke was well mixed in the smog chamber before UV lights were turned on for photo-oxidation. It is in the period before photo-oxidation and after bag filling, during which the initial aerosol was characterized, that we study in this paper. Further, we use the term "POA" to describe the mass concentration of organic compounds observed in the particle phase at the start of this period, as measured by the Q-AMS (i.e., $\mathrm{OA}$ at time $=0$ ).

\subsection{Model simulations}

We use a zero-dimensional (box) version of the TwOMoment Aerosol Sectional (TOMAS) microphysics model (Adams and Seinfeld, 2002; Pierce and Adams, 2009; Pierce et al., 2011) combined with particle and vapor wall-loss esti- mates to simulate the organic species phase partitioning during the FLAME III smog-chamber characterization experiments. TOMAS in this work simulates 36 logarithmically spaced size sections that span dry diameters from $3 \mathrm{~nm}$ to $10 \mu \mathrm{m}$. Simulated aerosol species include black carbon, water, and eight lumped organic aerosol species with logarithmically spaced effective saturation concentrations $\left(C^{*}\right)$ between $10^{-3}$ to $10^{4} \mu \mathrm{g} \mathrm{m}^{-3}$ according to the volatility basis set (VBS; Donahue et al., 2006) based on aerosol partitioning theory (Pankow, 1994). The model simulates eight vaporphase species that are the vapor components of the eight organic volatility basis set bins. Estimated molecular weights for these eight organic components followed the calculation method in Robinson et al. (2007). The model represents the CMU smog chamber as a single, well-mixed box, which implicitly assumes that mixing within the chamber occurs on faster timescales than wall losses. This fast-mixing assumption is justified as the turbulent-mixing timescale is on the order of seconds (based on $1 / k_{\mathrm{e}}$ derived from the Aerosol Parameterization Estimation, or APE model; see Table 1). The parameters used in our base-assumption simulations are shown in Table 2. These parameters, as well as sensitivities of these parameters that we explore, are discussed below.

For our base-assumption simulations as well as the sensitivity tests with perturbed parameters, we simulate all 18 smog-chamber experiments described in Table 1, using the average chamber temperature recorded during experimentation by Hennigan et al. (2011). For each simulated experiment, the initial volatility distribution of the wood-smoke POA is that proposed by May et al. (2013b) as shown in Fig. 1a. May et al. (2013b) fit thermodenuder data in the 18 experiments during FLAME III mentioned above to find the optimal combination of partitioning parameters $\left(f_{i}\right.$, $\Delta H_{\mathrm{vap}, i}$, and $\left.\alpha\right)$ across the 18 experiments. In the fitting procedure, May et al. (2013b) characterized the particle number loss in the thermodenuder by measuring the generated ammonium sulfate size distributions using an upstream and downstream SMPS and then apply the loss to correct the measured particulate organic data. However, the evaporation 

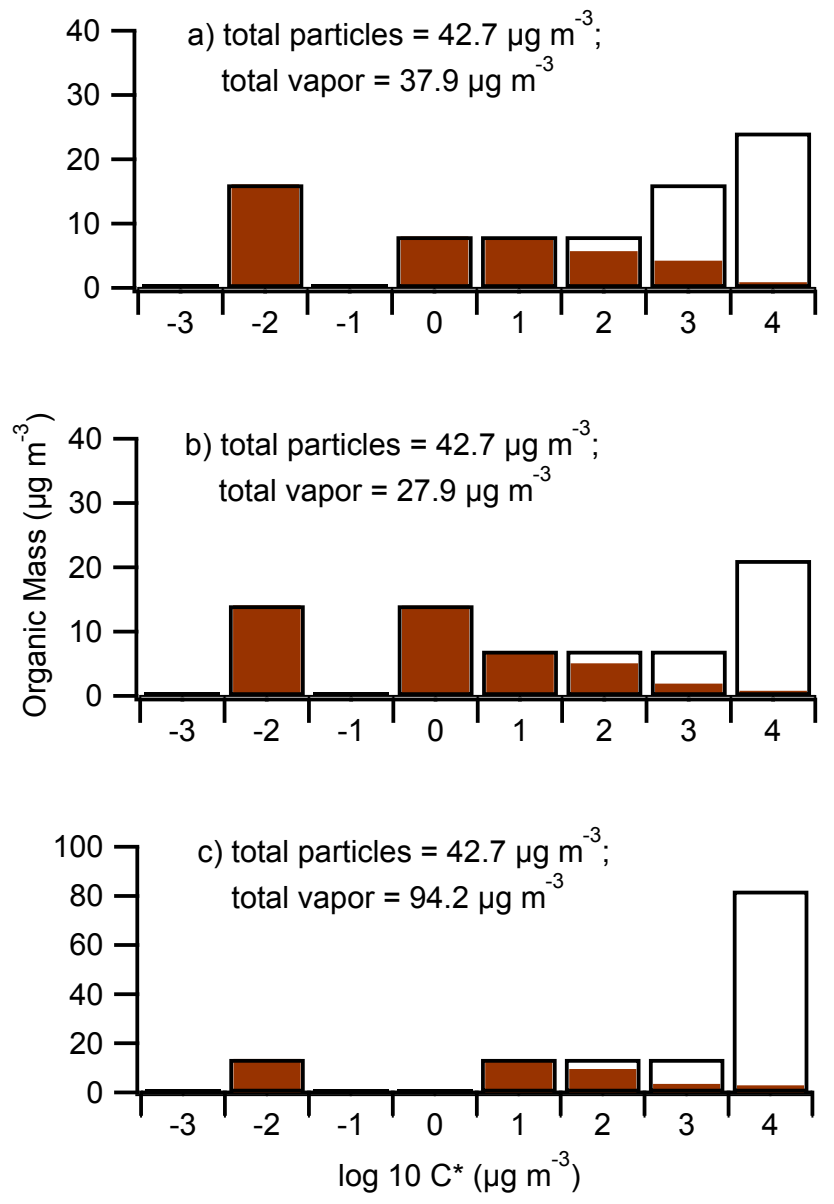

Figure 1. (a) Best-fit volatility distribution, (b) lower bound of volatility distribution and (c) upper bound of volatility distribution as reported in May et al. (2013) for a total initial average organic aerosol mass concentration of $42.7 \mu \mathrm{g} \mathrm{m}^{-3}$ over the 18 experiments. The shaded areas represent the organic mass in each volatility bin that is predicted to be in the aerosol phase, for average OC concentration.

of semi-volatile organics due to vapor-phase wall losses may have shifted the particle volatility to lower values with time in the chamber. Thus, the volatility distribution of biomass burning adopted from May et al. (2013b) may be weighted towards lower volatilities than those that entered the chamber, which means that vapor wall losses could be more important than calculated in this study. We test the model sensitivity to upper and lower bounds of their derived POA volatility distribution (representing the edges of the shaded region in Fig. 6a from May et al., 2013b, and shown here in Fig. 1).

Additional sources of uncertainty in modeling gas-phase wall losses are the gas-particle accommodation and gas-wall accommodation coefficients, which are used to modulate mass transfer rates between the gases and particles/walls. Different studies exploring the mass transfer rates have derived different values of the accommodation coefficients
(Greishop et al., 2007; Lee et al., 2011; Stanier et al., 2007; Saleh et al., 2013), and thus uncertainties in these accommodation coefficients need to be systematically explored in any study using models of gas-phase wall losses. In our base set of assumptions, we assume that the accommodation coefficient for mass transfer between the vapor and particle phases $\left(\alpha_{\mathrm{p}}\right)$ is 1 based on the May et al. (2013b) results (i.e., no mass transfer limitations; Table 2 ). We perform sensitivity simulations wherein we assume that $\alpha_{\mathrm{p}}$ is 0.01 and 0.001 , as these values were found to be necessary to reproduce mass transfer in other studies (Grieshop et al., 2007; Stanier et al., 2007; Lee et al., 2011; Saleh et al., 2013; McVay et al., 2014). However, these lower effective accommodation coefficients were used in the studies of SOA formation and may not be appropriate for the POA partitioning, because we are unaware of observed mass transfer limitations in fresh POA, but they provide a logical sensitivity test. Uncertainties in the accommodation coefficients between the vapors and the wall are discussed below.

For each of the 18 experiments, we estimate the sizedependent particle wall loss $\left(k_{\mathrm{w}, \mathrm{p}}\left(D_{\mathrm{p}}\right)\right)$ by applying the APE model on SMPS measurements following the procedure described in Pierce et al. (2008). Briefly, the APE model determines the best fit of the time- and size-dependent particlephase wall loss following Eq. (1).

$k_{\mathrm{w}, \mathrm{p}}\left(D_{\mathrm{p}}\right)=k_{\mathrm{w}, \mathrm{p} 0}+\frac{6 \sqrt{k_{\mathrm{e}} D}}{\pi R} D_{1}\left(\frac{\pi \gamma_{s}}{2 \sqrt{k_{\mathrm{e}} D}}\right)+\frac{v_{\mathrm{s}}}{4 R / 3}$,

where $k_{\mathrm{e}}\left(\mathrm{s}^{-1}\right)$ is a function of the turbulent kinetic energy in the chamber (Crump and Seinfeld, 1981), D is the Brownian diffusivity of the particle of size $D_{\mathrm{p}}, R$ is the radius of the chamber, $v_{\mathrm{s}}$ is the gravitational settling velocity of the particle, and $k_{\mathrm{w}, \mathrm{p} 0}$ is a size-independent wall-loss rate that is used to represent the effect of electrostatic forces on the wall loss, which tends to make particle wall losses less size dependent than turbulent wall losses would predict (Pierce et al., 2008). $D_{1}$ is the Debye function (Aramowitz and Stegun, 1964). We use non-linear least-squares fitting optimization to best estimate the condensation/evaporation and wall-loss parameters in the APE model. The goal of fitting optimization is to minimize $X^{2}$ as follows:

$X^{2}=\sum_{a=1}^{3}\left(\frac{\left(M_{i(a), \mathrm{p}}-M_{i(a), \mathrm{o}}\right)}{M_{i(a), \mathrm{o}}}\right)^{2}$,

where $i(a)$ is the set of total diameter moments $(0,1.5,3)$. The chosen range of moments ensures the model fits both the total number (0th moment) and the total volume (proportional to the $3 \mathrm{rd}$ moment). The subscripts $\mathrm{p}$ and o indicate the predicted and observed moments, respectively. Derived $k_{\mathrm{w} 0}$ and $k_{\mathrm{e}}$ for 18 experiments are listed in Table 1. Calculated wall-loss rates $\left(k_{\mathrm{W}}, \mathrm{s}^{-1}\right)$ for the 18 experiments are generally consistent with each other as shown in Fig. S2. For times when the SMPS is sampling from the thermodenuder 
Table 3. Molecular weight $\left(\mathrm{g} \mathrm{mol}^{-1}\right)$ associated with each vapor pressure bin, computed for a temperature of $298 \mathrm{~K}$ following the calculation equation in Table 2 , varying $C_{\mathrm{w}} / M_{\mathrm{w}} \gamma_{\mathrm{w}}$ as a function of vapor pressure bins, wall-loss rates $\left(\mathrm{s}^{-1}, k_{\mathrm{w}, \mathrm{on}}\right.$ and $k_{\mathrm{w}, \text { off }}$ for $120,9 \mu \mathrm{mole} \mathrm{m}^{-3}$ and varying $\left.C_{\mathrm{w}} / M_{\mathrm{w}} \gamma_{\mathrm{w}}\right)$ and accommodation coefficients between gas and wall $\left(\alpha_{\mathrm{w}}\right)$ for each volatility bin in the base-assumption simulation and the sensitivity tests.

\begin{tabular}{|c|c|c|c|c|c|c|c|c|}
\hline$C_{i}^{*}\left(\mu \mathrm{g} \mathrm{m}^{-3}\right)$ & $10^{-3}$ & $10^{-2}$ & $10^{-1}$ & $10^{0}$ & $10^{1}$ & $10^{2}$ & $10^{3}$ & $10^{4}$ \\
\hline Molecular weight $\left(\mathrm{g} \mathrm{mol}^{-1}\right)$ & 569 & 524 & 479 & 434 & 389 & 344 & 299 & 254 \\
\hline varying $C_{\mathrm{w}} / M_{\mathrm{w}} \gamma_{\mathrm{w}}^{1}$ & $1.30 \times 10^{-6}$ & $9.16 \times 10^{-5}$ & $6.44 \times 10^{-4}$ & $4.53 \times 10^{-3}$ & $3.18 \times 10^{-2}$ & $2.24 \times 10^{-1}$ & 1.57 & 11.1 \\
\hline$\alpha_{\mathrm{w}, \text { base }}$ & $1.0 \times 10^{-5}$ & $1.0 \times 10^{-5}$ & $1.0 \times 10^{-5}$ & $1.0 \times 10^{-5}$ & $1.0 \times 10^{-5}$ & $1.0 \times 10^{-5}$ & $1.0 \times 10^{-5}$ & $1.0 \times 10^{-5}$ \\
\hline$\alpha_{\mathrm{w}, \mathrm{sens}} 4$ & $1.80 \times 10^{-6}$ & $1.16 \times 10^{-6}$ & $7.45 \times 10^{-7}$ & $4.79 \times 10^{-7}$ & $3.08 \times 10^{-7}$ & $1.98 \times 10^{-7}$ & $1.27 \times 10^{-7}$ & $8.17 \times 10^{-8}$ \\
\hline$k_{\mathrm{w}, \mathrm{on}}\left(\right.$ base, $\mathrm{s}^{-1}$ ) & $7.33 \times 10^{-4}$ & $7.58 \times 10^{-4}$ & $7.86 \times 10^{-4}$ & $8.18 \times 10^{-4}$ & $8.54 \times 10^{-4}$ & $8.97 \times 10^{-4}$ & $9.47 \times 10^{-4}$ & $1.01 \times 10^{-3}$ \\
\hline$k_{\mathrm{w}, \mathrm{off}}\left(\mathrm{s}^{-1}, 120 \mu \mathrm{mol} \mathrm{m}^{-3}\right)^{2}$ & $1.07 \times 10^{-11}$ & $1.21 \times 10^{-10}$ & $1.37 \times 10^{-9}$ & $1.57 \times 10^{-8}$ & $1.83 \times 10^{-7}$ & $2.17 \times 10^{-6}$ & $2.64 \times 10^{-5}$ & $3.31 \times 10^{-4}$ \\
\hline$k_{\mathrm{w}, \mathrm{off}}\left(\mathrm{s}^{-1}, 9 \mu \mathrm{mol} \mathrm{m}^{-3}\right)^{3}$ & $7.01 \times 10^{-11}$ & $8.09 \times 10^{-10}$ & $9.44 \times 10^{-9}$ & $1.11 \times 10^{-7}$ & $1.33 \times 10^{-6}$ & $1.62 \times 10^{-5}$ & $2.02 \times 10^{-4}$ & $2.59 \times 10^{-3}$ \\
\hline$k_{\mathrm{w}, \text { off }}\left(\mathrm{s}^{-1} \text {, varying } C_{\mathrm{w}} / M_{\mathrm{w}} \gamma_{\mathrm{w}}\right)^{1}$ & $3.95 \times 10^{-4}$ & $6.31 \times 10^{-4}$ & $1.02 \times 10^{-3}$ & $1.67 \times 10^{-3}$ & $2.76 \times 10^{-3}$ & $4.66 \times 10^{-3}$ & $8.04 \times 10^{-3}$ & $1.43 \times 10^{-2}$ \\
\hline$k_{\mathrm{w}, \mathrm{on}}\left(\mathrm{s}^{-1}, \alpha_{\mathrm{w}, \mathrm{sens}}\right)^{4}$ & $1.55 \times 10^{-4}$ & $1.05 \times 10^{-4}$ & $7.15 \times 10^{-5}$ & $4.86 \times 10^{-5}$ & $3.31 \times 10^{-5}$ & $2.27 \times 10^{-5}$ & $1.56 \times 10^{-5}$ & $1.09 \times 10^{-5}$ \\
\hline$k_{\mathrm{w}, \mathrm{off}}\left(\mathrm{s}^{-1}, \alpha_{\mathrm{w}, \mathrm{sens}}\right)^{4}$ & $2.27 \times 10^{-12}$ & $1.68 \times 10^{-12}$ & $1.24 \times 10^{-11}$ & $9.32 \times 10^{-10}$ & $7.09 \times 10^{-9}$ & $5.50 \times 10^{-8}$ & $4.36 \times 10^{-7}$ & $3.59 \times 10^{-6}$ \\
\hline$k_{\mathrm{w}, \mathrm{on}}\left(\mathrm{s}^{-1}, \alpha_{\mathrm{w}}\right.$, of $\left.1 \times 10^{-4}\right)$ & $2.77 \times 10^{-3}$ & $2.81 \times 10^{-3}$ & $2.85 \times 10^{-3}$ & $2.89 \times 10^{-3}$ & $2.94 \times 10^{-3}$ & $2.99 \times 10^{-3}$ & $3.05 \times 10^{-3}$ & $3.12 \times 10^{-3}$ \\
\hline$k_{\mathrm{w}, \mathrm{off}}\left(\mathrm{s}^{-1}, \alpha_{\mathrm{W}}\right.$ of $\left.1 \times 10^{-4}\right)$ & $4.06 \times 10^{-11}$ & $4.47 \times 10^{-10}$ & $4.96 \times 10^{-9}$ & $5.55 \times 10^{-8}$ & $6.30 \times 10^{-7}$ & $7.25 \times 10^{-6}$ & $8.51 \times 10^{-5}$ & $1.02 \times 10^{-3}$ \\
\hline$k_{\mathrm{w}, \text { on }}\left(\mathrm{s}^{-1}, \alpha_{\mathrm{w}}\right.$ of $\left.1 \times 10^{-2}\right)$ & $3.99 \times 10^{-3}$ & $4.00 \times 10^{-3}$ & $4.01 \times 10^{-3}$ & $4.01 \times 10^{-3}$ & $4.02 \times 10^{-3}$ & $4.03 \times 10^{-3}$ & $4.04 \times 10^{-3}$ & $4.06 \times 10^{-3}$ \\
\hline$k_{\mathrm{w}, \mathrm{off}}\left(\mathrm{s}^{-1}, \alpha_{\mathrm{w}}\right.$ of $\left.1 \times 10^{-2}\right)$ & $5.85 \times 10^{-11}$ & $6.36 \times 10^{-10}$ & $6.97 \times 10^{-9}$ & $7.70 \times 10^{-8}$ & $8.61 \times 10^{-7}$ & $9.76 \times 10^{-6}$ & $1.13 \times 10^{-4}$ & $1.33 \times 10^{-3}$ \\
\hline$k_{\mathrm{w}, \mathrm{on}}\left(\mathrm{s}^{-1}, \alpha_{\mathrm{w}}\right.$ of 1$)$ & $4.01 \times 10^{-3}$ & $4.02 \times 10^{-3}$ & $4.02 \times 10^{-3}$ & $4.03 \times 10^{-3}$ & $4.03 \times 10^{-3}$ & $4.04 \times 10^{-3}$ & $4.06 \times 10^{-3}$ & $4.07 \times 10^{-3}$ \\
\hline$k_{\mathrm{w}, \mathrm{off}}\left(\mathrm{s}^{-1}, \alpha_{\mathrm{w}}\right.$ of 1$)$ & $5.88 \times 10^{-11}$ & $6.39 \times 10^{-10}$ & $7.00 \times 10^{-9}$ & $7.73 \times 10^{-8}$ & $8.64 \times 10^{-7}$ & $9.80 \times 10^{-6}$ & $1.13 \times 10^{-4}$ & $1.34 \times 10^{-3}$ \\
\hline
\end{tabular}

(rather than directly from the bag), we linearly interpolated the concentration in each SMPS size bin in time between the previous and following measurement made directly from the bag. Further, to reduce noise in the APE model, we smooth the concentration in each SMPS size section (both the direct measurements and interpolated data) using a nine-point moving time average. Table 1 lists the derived $k_{\mathrm{e}}$ and $k_{\mathrm{w}, \mathrm{p} 0}$ for the 18 experiments.

In the simulations, we assume vapor wall loss to be reversible. The rate coefficient for gross transfer of gas-phase species onto the walls is described as $k_{\mathrm{w}, \mathrm{on}}$ (McMurry and Grosjean, 1985; Zhang et al., 2014):

$k_{\mathrm{w}, \text { on }}=\left(\frac{A}{V}\right) \frac{\left(\frac{\alpha_{\mathrm{w}} \bar{c}}{4}\right)}{1.0+\left(\frac{\pi}{2}\right)\left[\frac{\alpha_{\mathrm{w}} \bar{c}}{4\left(k_{\mathrm{e}} D_{\mathrm{gas}}\right)^{0.5}}\right]}$,

where $A / V$ is the surface to volume ratio of the chamber, $\alpha_{\mathrm{w}}$ is the mass accommodation coefficient of vapors onto the chamber walls, $\bar{c}\left(\mathrm{~m} \mathrm{~s}^{-1}\right)$ is the mean thermal speed of the molecules (calculated using the molecular weights of each organic volatility bin), $k_{\mathrm{e}}$ is a function of the turbulent kinetic energy in the chamber (derived from the APE model described above), and $D_{\text {gas }}$ is the molecular diffusivity $\left(\mathrm{m}^{2} \mathrm{~s}^{-1}\right)$. As a base assumption for the accommodation coefficient $\alpha_{\mathrm{w}}$, we assume $1 \times 10^{-5}$, adopted from Matsunaga and Ziemann (2010), for all volatility bins. We perform sensitivity simulations where (1) we use alternate accommodation coefficient values that depend on volatility, based on Zhang et al. (2015) and as shown in Table 3 and (2) take constant values of $1 \times 10^{-4}, 1 \times 10^{-2}$ and 1 , respectively, to explore the uncertainty in the accommodation coefficient.
The gross evaporation rate coefficient from the wall is $k_{\mathrm{w}, \text { off }}$ (Matsunaga and Ziemann, 2010):

$k_{\mathrm{w}, \text { off }}=\frac{k_{\mathrm{w}, \text { on }}}{K_{\mathrm{w}} C_{\mathrm{w}}}=k_{\mathrm{w}, \text { on }}\left(\frac{C^{*} M_{\mathrm{w}} \gamma_{\mathrm{w}}}{C_{\mathrm{w}} M_{\mathrm{p}} \gamma_{\mathrm{p}}}\right)$,

where $K_{\mathrm{w}}$ is the gas-particle partitioning coefficient, $C_{\mathrm{w}}$ is the equivalent or effective organic mass concentration of the walls (in units of mass per chamber volume), $C^{*}$ is the saturation concentration $\left(\mu \mathrm{g} \mathrm{m}^{-3}\right), M_{\mathrm{p}}$ and $M_{\mathrm{w}}$ are the average molecular weights of the organic species in the particles and in the Teflon film comprising the chamber $\left(\mu \mathrm{g} \mathrm{m}^{-3}\right)$, and $\gamma_{\mathrm{w}}$ and $\gamma_{p}$ are the activity coefficients of the organic species in the Teflon film and the particle, respectively. $\gamma_{p}$ is assumed to be unity. $C_{\mathrm{w}} / M_{\mathrm{w}} \gamma_{\mathrm{w}}$ was measured to be $9,20,50$ and $120 \mu$ mole m$^{-3}$ for n-alkanes, 1-alkenes, 2-alcohols, and 2ketones, respectively (Matsunaga and Ziemann, 2010). $C_{\mathrm{w}}$ was also found to have positive correlation with volatility of organics, spanning 5 orders in Zhang et al. (2015). As our base assumption, we use $120 \mu$ mole $\mathrm{m}^{-3}$ for this parameter. We also perform sensitivity simulations where we assume the values of $9,20,50 \mu \mathrm{mole}^{-3}$ and $C_{\mathrm{w}} / M_{\mathrm{w}} \gamma_{\mathrm{w}}$ as a function of $C_{i}^{*}$ (following Zhang et al., 2015) in a series of sensitivity tests. The $k_{\mathrm{w}, \text { off }}$ values for each volatility bin using 120 , $9 \mu$ mole $\mathrm{m}^{-3}$ and varying $C_{\mathrm{w}} / M_{\mathrm{w}} \gamma_{\mathrm{w}}$ are shown in Table 3. Finally, in our base simulations, we assume that the modeled particles and vapors are in equilibrium at the start of the experiment in the CMU smog chamber. However, as the CMU chamber was filled, smoke from the FSL burning chamber was diluted by $\sim 25: 1$, which would make the vapor-phase organics sub-saturated with respect to the particle phase. As a sensitivity test, we assume that particles and vapor are in equilibrium in the FSL burning chamber, and that the CMU 
Table 4. Sensitivity tests varying the input parameters.

\begin{tabular}{ll}
\hline Parameter & Range of observations \\
\hline a. Volatility distribution & May et al. (2013b) best fit; upper and lower envelopes (see Fig. 2 for details) \\
\hline $\begin{array}{l}\text { b. Effective wall saturation } \\
\text { concentration } \\
\left(C_{\mathrm{w}} / M_{\mathrm{w}} \gamma_{\mathrm{w}}, \mu \text { mole } \mathrm{m}^{-3}\right)\end{array}$ & $\begin{array}{l}9,20,50, \text { and } 120 \text { for n-alkanes, 1-alkenes, 2-alcohols, and 2-ketones, respectively, } \\
\text { after Matsunaga and Ziemann (2010), } \\
\text { as a function of saturation concentration }\left(C_{i}^{*}\right) \text { (adapted from Zhang et al., 2015) }\end{array}$ \\
\hline $\begin{array}{l}\text { c. Accommodation coefficient for vapor } \\
\text { with the wall }\left(\alpha_{\mathrm{w}}\right) \text { and particles }\left(\alpha_{\mathrm{p}}\right)\end{array}$ & $\begin{array}{l}\text { Proposed as a function of saturation concentration }\left(C_{i}^{*}\right)(\text { Zhang et al., 2015) } \\
0.01 \text { and 0.001 as suggested by McVay et al. (2014) }\end{array}$ \\
\hline d. Dilution process & $\begin{array}{l}\text { Particles and vapor assumed in equilibrium before being diluted by } 25: 1 \text { when filling the smog } \\
\text { chamber (in other simulations, the particles and vapor were assumed to be in equilibrium } \\
\text { immediately after dilution.) }\end{array}$ \\
\hline
\end{tabular}

smog chamber is filled instantly as the FSL smoke is diluted by $25: 1$. It is not clear if this sensitivity study is a better assumption than our base assumption (particles and vapors start in equilibrium in the CMU chamber) as the CMU smog chamber was actually filled over $30 \mathrm{~min}$ and thus particles and vapors will move towards equilibrium (and particles and vapors will also be lost to the walls) during these $30 \mathrm{~min}$. However, since we do not know the actual vapor-phase concentrations at the time when the CMU chamber is full and particle-phase measurements start, we are left with these two assumptions for bounding our results. The parameters used in the TOMAS model for our base simulations are listed in Tables 1 and 2, and the properties of the eight organic volatility bins are shown in Table 3 . The sensitivity simulations that we perform are summarized in Table 4.

In addition, previous studies have assumed equilibrium between semi-volatile vapors and particles deposited to the walls in the chamber studies (e.g. Weitkamp et al., 2007; Hennigan et al., 2011), as mentioned in the Introduction section. We tested the influence of this equilibrium on the OA and vapor net loss after $1 \mathrm{~h}$ evolution. In the test, we assume that the equilibrium between semi-volatile vapors and wall-bound particle is similar to that between vapors and suspended particles in the chamber, independent of the effective wall mass/wall material. The condensation/evaporation of vapors to/from particles on the wall are treated as identical to suspended particles of the same size (i.e. we assume that the particles on the wall undergo identical gas-particle partitioning and mass transfer as the suspended particles). The test results show that the percent difference between the mean of basic assumption simulations and measurements across the 18 experiments is within $1 \%$. The buildup of wall-deposited particles and vapor on the wall of the chamber that is retained between experiments might have impacted the observations we used to initialize and compare with our simulations. We therefore modeled this potential influence by retaining the wall-deposited particles and vapors and repeating the same flush/fill experiment 10 times, simulating $12 \mathrm{~h}$ of "flushing" (the particle and vapor concentrations in the volume of the chamber set to 0 ) between experiments. In these 10-repeat tests, the 10th experiment had an increase of $8.8 \%$ in OM in the suspended particle phase and $2.9 \%$ in the vapor phase due to the slow and thus incomplete evaporation of the walldeposited compounds during the flushing process, and the resulting buildup of particles/vapor on the walls slowing vapor deposition to the walls in the subsequent "experiment" (Fig. S3). These results suggest that after a number of experiments, the accumulated wall-deposited particles and vapor in the chamber could have some influence on the next set of experiments even after the chamber was flushed overnight. However, since we do not know the history of the bag outside of these FLAME III experiments, we do not attempt to account for these effects in this modeling study but suggest they may represent an important uncertainty in SOAformation studies and should be explored.

\section{Results and discussions}

\subsection{Base assumption simulations of particle and vapor wall loss}

Figure 2 shows the evolution of particle number, total aerosol mass, and OA mass concentrations for the simulations and measurements of the 18 experiments (symbols represent the mean values of the 18 experiments, and the error bars show the standard deviations of the variability across the 18 experiments) for the base model assumptions (Tables 1, 2 and 3). The top panels show the results for the nine experiments with a higher initial organic mass fraction $(\mathrm{OF}, \mathrm{OF}>0.8$, shown in Table 1) and the bottom panels show the nine experiments with a lower organic fraction $(\mathrm{OF}<0.8)$. The choice of OF of 0.8 as a cutoff was simply to split the experiments evenly. Overall, the evolution of the mean trends and standard deviations of aerosol number, mass and OA mass concentrations are captured by the model when both the particleand vapor-phase wall losses are simulated (blue lines). Because the total time of POA characterization differed in the 18 experiments, $1 \mathrm{~h}$ is used as the cutoff time to evaluate 


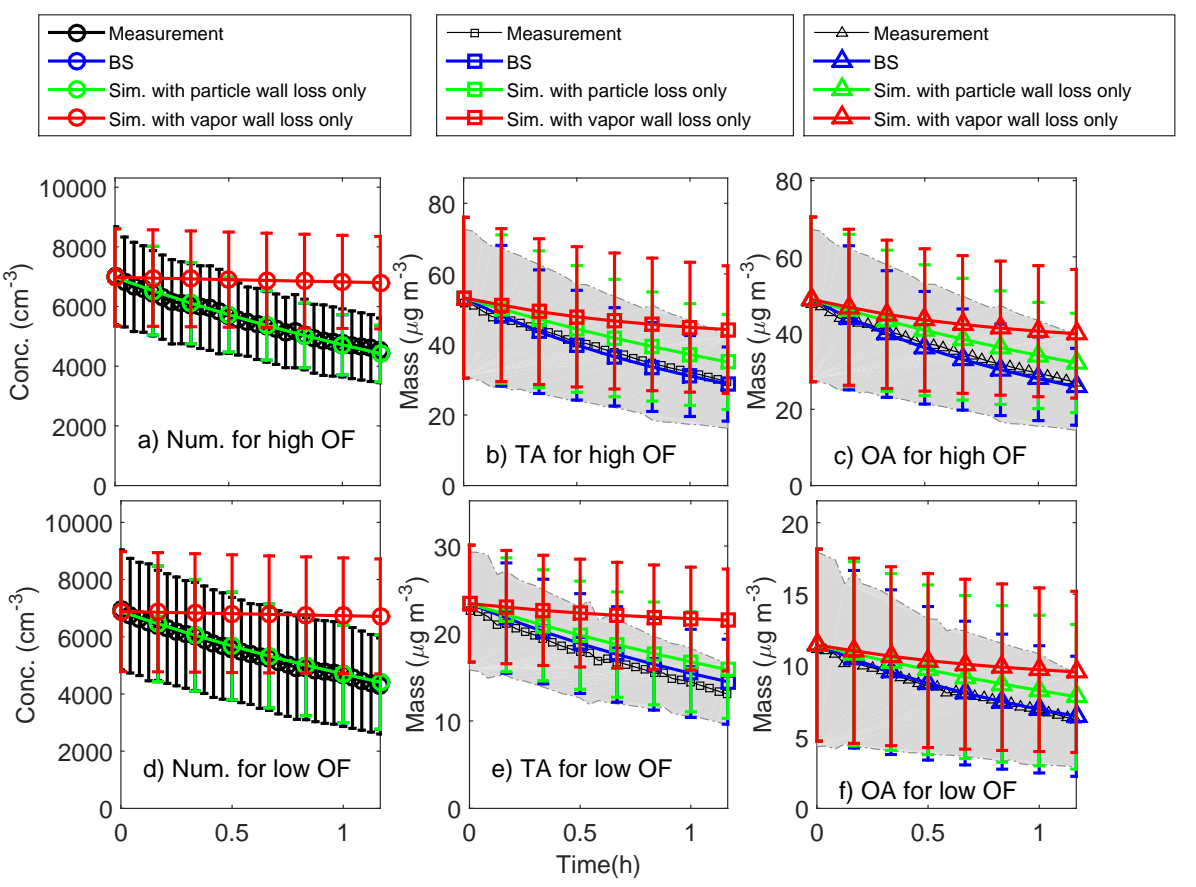

Figure 2. Comparison between the average of the measurements and the average of the model simulations of the 18 experiments for (a) particle number concentration $\left(\mathrm{cm}^{-3}\right)$, (b) total submicron aerosol mass concentration $\left(\mathrm{TA}, \mu \mathrm{g} \mathrm{m} \mathrm{m}^{-3}\right)$ and (c) organic aerosol mass concentration $\left(\mathrm{OA}, \mu \mathrm{g} \mathrm{m}^{-3}\right)$ for the burns with high aerosol organic mass fraction, OF $>0.8$; (d) $-(\mathbf{f})$ as in (a)-(c), but for the burns with low aerosol organic mass fraction, $\mathrm{OF}<0.8$. Burns with $\mathrm{OF}>0.8$ included burns 37, 38, 40, 47, 51, 57, 61, 65 and 66; the low-OF experiments were burns 42, 43, $45,49,53,55,59,63$, and 67 . The error bars and shaded areas represent 1 standard deviation in the measurements and the model simulations, respectively, and represent variations between the various experiments rather than uncertainties.

the simulation results. The percent bias between the mean of these base-assumption simulations and measurements after $1 \mathrm{~h}$ of evolution is $-1.4,-3.1$ and $-4.8 \%$ for number, TA and OA, respectively, for the high-OF experiments and $0.94,6.6$ and $-0.12 \%$ for the low-OF experiments (Table 5). The percent bias between the standard deviations of these base-assumption simulations and measurements is 11,22 and $21 \%$ for number, TA and OA, respectively, for the high-OF experiments and $4.9,31$ and $15 \%$ for the low-OF experiments (Table 5). These biases show that the TOMAS model generally captures the number and mass loss for the high$\mathrm{OF}$ and low-OF experiments. The measured TA concentration was calculated from OA measurements using the initial OA / TA ratio, assuming an unchanged OA / TA over the course of the experiments. This assumption may be the reason for a high bias in TA in the low-OF burns at the end of the simulations (panel e) because the final OA / TA ratio will be lower than the initial due to vapor losses and subsequent $\mathrm{OA}$ evaporation. Thus, the "measured TA" for the low-OF burns should be viewed as uncertain and likely biased low.

Figure 3 shows the modeled evolution of organics between the particle phase, vapor phase and the wall for the mean and standard deviation of the 18 simulations (panel a) along with the overall mass budget and the budgets for specific processes, integrated over the simulation (panel b). Modeled organic vapor concentrations decrease rapidly, due to vapor loss to the walls, while mass lost due to particle deposition to the walls is much lower in our base simulations (Fig. 3a). We estimate that the organic vapor concentration decreases by $86 \pm 2.0 \%$ of the initial vapor concentration on average, driven by these losses to the walls and only partially compensated for by evaporation of particles, which decreases particulate-phase mass concentrations and replenishes some of the lost vapor. $41 \pm 4.8 \%$ of the total initial particulatephase organic mass is lost, with $65 \%$ of this mass loss attributed to direct particle deposition to the walls, and $35 \%$ from particle evaporation driven by the wall loss of vapors (Fig. 3b). The removal of vapors to the walls perturbs the initial particle-gas equilibrium sub-saturating the vapor phase with respect to the particles and thus leads to evaporation from the particulate phase; thus, particle-organic evaporation is estimated to play a relatively important role in the total loss of particle-phase organic mass during the experiments under our base assumptions.

Note that as long as the vapors are supersaturated with respect to the walls (i.e., $k_{\text {off }}<k_{\text {on }}$ ), the uptake of vapors to the wall will continue to keep the vapors sub-saturated with respect to the particles, and the particles will continue to evaporate (until they have entirely evaporated). This evaporation of the particles due to vapor uptake by the walls is analogous 
Table 5. The percent bias between the mean and the standard deviations of these simulations (including base-assumption simulation and other sensitivity tests) and measurements after $1 \mathrm{~h}$ of evolution.

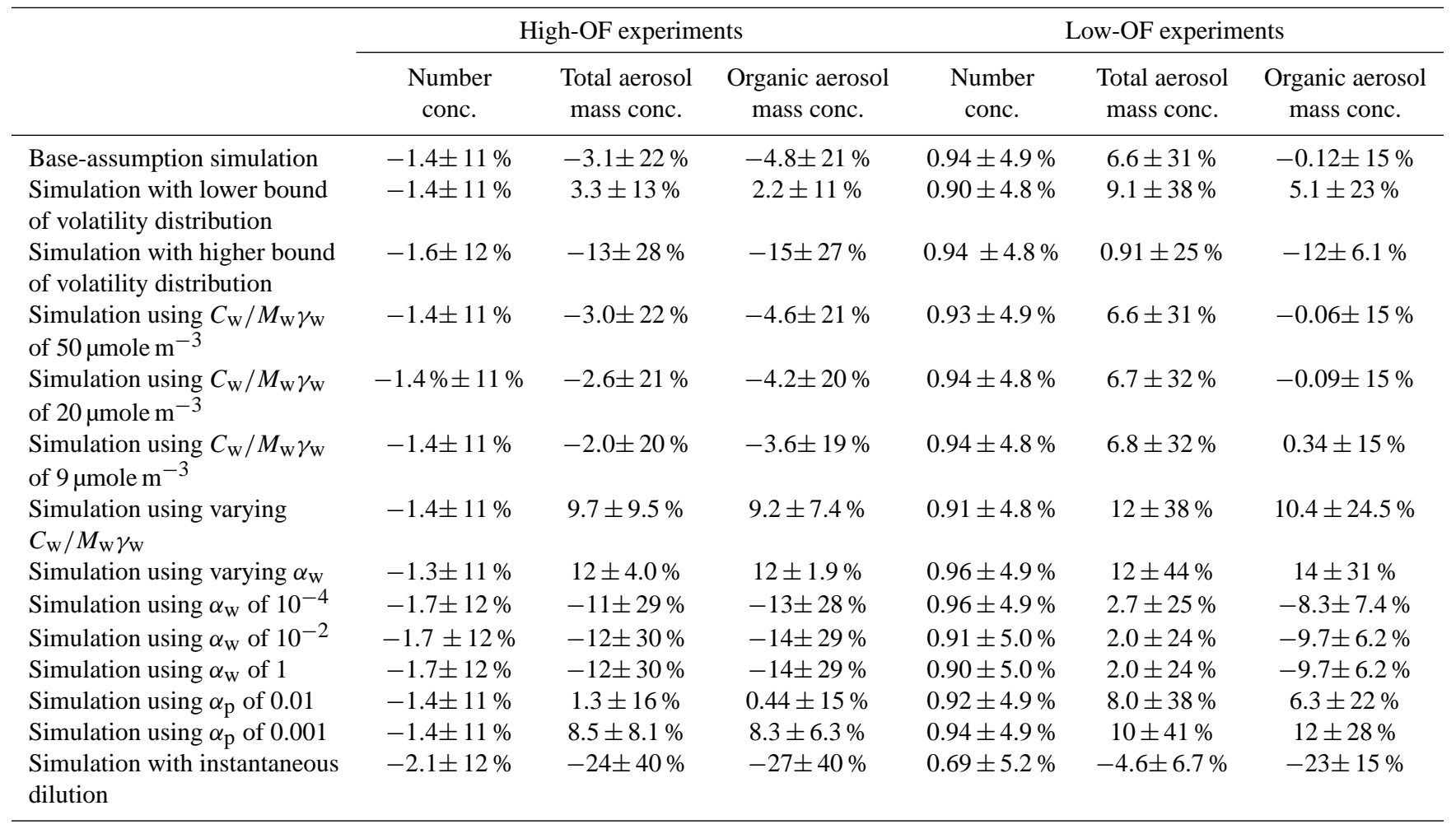

(a)

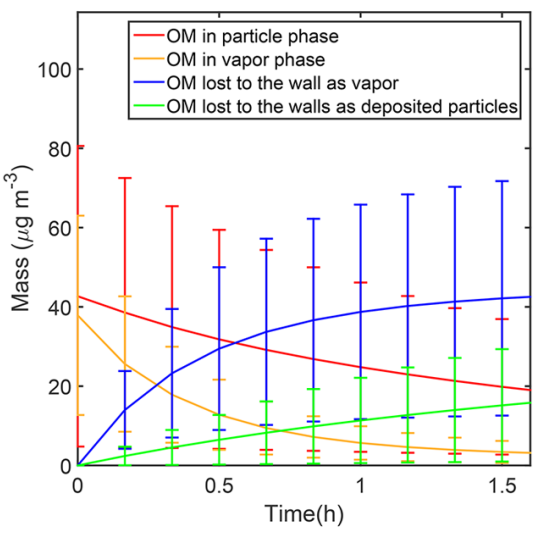

(b)

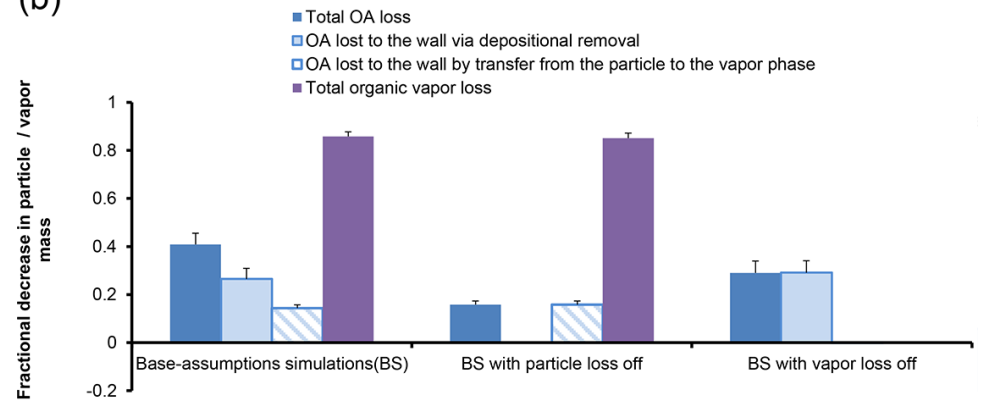

Figure 3. (a) Time evolution of organic mass $(\mathrm{OM})$ in the particle and vapor phases, and vapor- and particle-phase losses to the chamber walls averaged over the 18 simulations with base assumptions (in units of $\mu \mathrm{g} \mathrm{m}^{-3}$; the mass of particles and vapor on the wall has been normalized by the volume of the bag); (b) organic species budgets for the base simulation and two sensitivity studies. The vertical bars show the fraction of the initial assumed total organic aerosol (OA) that is removed from the chamber volume during the 75 min simulation period (blue); lost to the walls via depositional removal of particles (light blue); transferred from the particle phase to the vapor phase (blue hatched). The blue bars have been normalized by the initial particulate organic mass. The purple bars show the total fractional organic vapor that is removed from the chamber during the simulation period. The error bars represent 1 standard deviation in the simulations of the 18 burns and represent burn-to-burn variability.

to the Bergeron-Findeisen process in mixed-phase clouds where liquid droplets evaporate and ice crystals grow: the vapor pressure of water with respect to ice is lower than the vapor pressure with respect to water, and in our experiments the organic vapor pressure with respect to the walls is lower than the respect to the particles. In our base-assumption calculations, $k_{\text {off }} \ll k_{\text {on }}$ throughout the experiments, which high- 


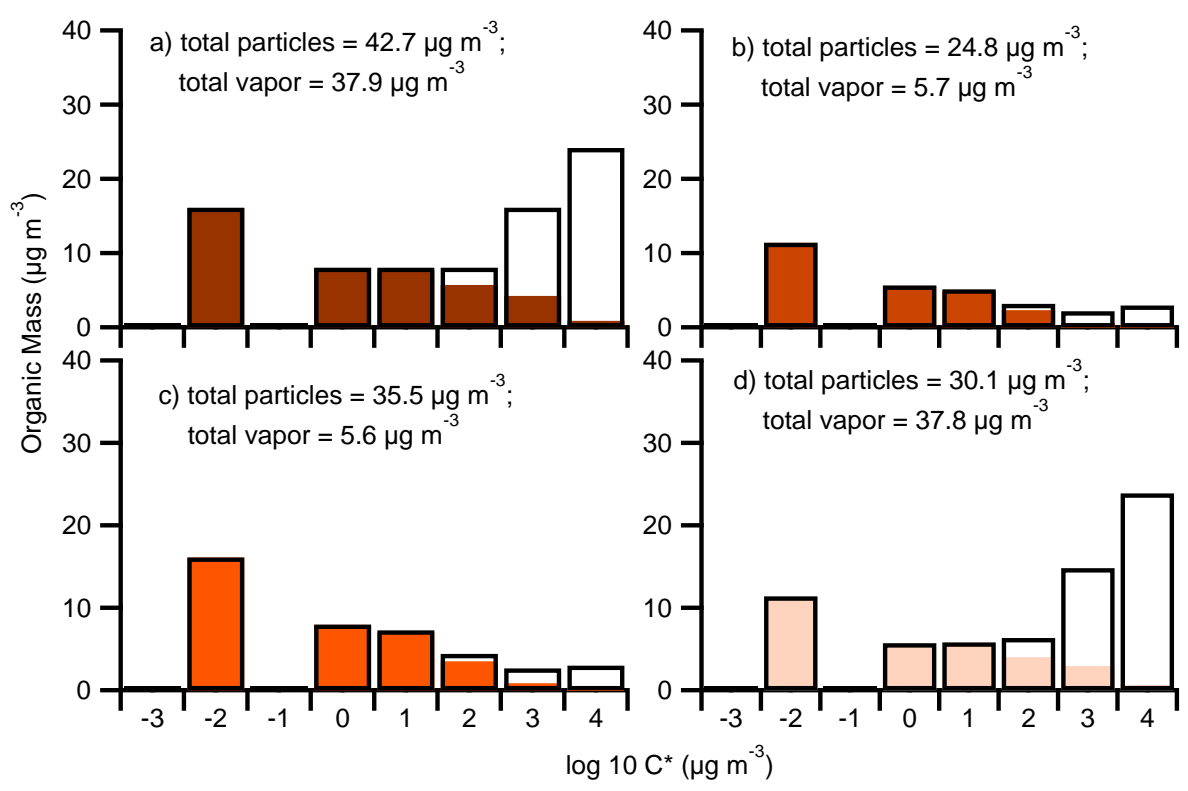

Figure 4. The total organic mass concentration, distributed into its volatility bins, at (a) initial time, i.e., the distribution recommended in May et al. (2013b), for a total initial average organic aerosol mass concentration of $42.7 \mu \mathrm{g} \mathrm{m}^{-3}$ over the 18 experiments; at the end of the $1 \mathrm{~h}$ simulation for (b) the base-assumption simulations; (c) the simulation in which particle losses to the walls were turned off; (d) the simulation in which vapor losses to the walls were turned off. Height of bars represents the total mass expected for that volatility bin. Solid regions in the bars represent the organic mass present in the particle phase and open regions represent the mass in the vapor phase.

lights the large vapor-uptake capacity of walls as discussed in Yeh and Ziemann (2014).

We perform additional tests where we turn particle and vapor losses off individually to evaluate the influence of the two mechanisms on each other (Figs. 2 and 3b). When particle loss is turned off, mass loss of particles through evaporation increases by $10 \%$ over the course of the $60 \mathrm{~min}$ simulation, due to the higher particle surface area retained suspended in the chamber, which allows for faster evaporation. When vapor loss is turned off, $10 \%$ more mass is lost by particle wall loss than in the base simulation. Note that for the results shown in Fig. 2, neither particle nor vapor wall losses alone can explain the OA or TA mass lost in the experiments using our base assumptions. On the other hand, particle wall losses alone account for the particle number concentration losses during the experiment, as expected.

The mean (across the 18 experiments) changes in the volatility distributions of organic species for the baseassumption simulations and for the scenarios with particle and vapor wall losses on/off are shown in Fig. 4. In our simulations including vapor wall losses (Fig. $4 \mathrm{~b}$ and c), the vapor-phase organic species are almost entirely removed to the walls. Furthermore, the remaining particle-phase species are shifted to those with lower volatilities due to evaporation of the higher volatility compounds $\left(C^{*}\right.$ of $10^{2}$ through $10^{4}$ ). The strong loss of these semi-volatile vapors, if they are SOA precursors, suggests that SOA production as observed in these wood-smoke smog-chamber experiments may have been biased low, or may have proceeded only through certain precursors that were not strongly removed by these processes. We will explore these SOA-production biases in future work.

\subsection{Sensitivity tests on the model parameters}

We perform a series of sensitivity tests for several model parameters to determine if the results for the base assumptions are robust to various uncertainties. As described above, our sensitivity parameters are the initial volatility distribution, the effective wall saturation concentration coefficients $\left(C_{\mathrm{w}} / M_{\mathrm{w}} \gamma_{\mathrm{w}}\right)$, the accommodation coefficients for vapor species absorbed into the walls and into particles, and the possible effects of dilution while filling the chamber (Table 4).

\subsubsection{Effect of volatility distribution bounds}

The upper and lower bounds of volatility distribution that we test were derived based on the experimental uncertainty in the study of May et al. (2013b). The lower- and upper-bound volatility distributions are shown in Fig. $1 \mathrm{~b}$ and c. Figure 5 shows the comparison of the model to the measurements for these initial distributions. The percent bias between the mean $\mathrm{OA}$ of these simulations and measurements is $-15,-4.8$ and $2.2 \%$ for the higher-bound, base and lower-bound distributions, respectively, for high-OF experiments and $-12,-0.12$ and $5.1 \%$ for low-OF experiments (Table 5). Thus, the lower- 

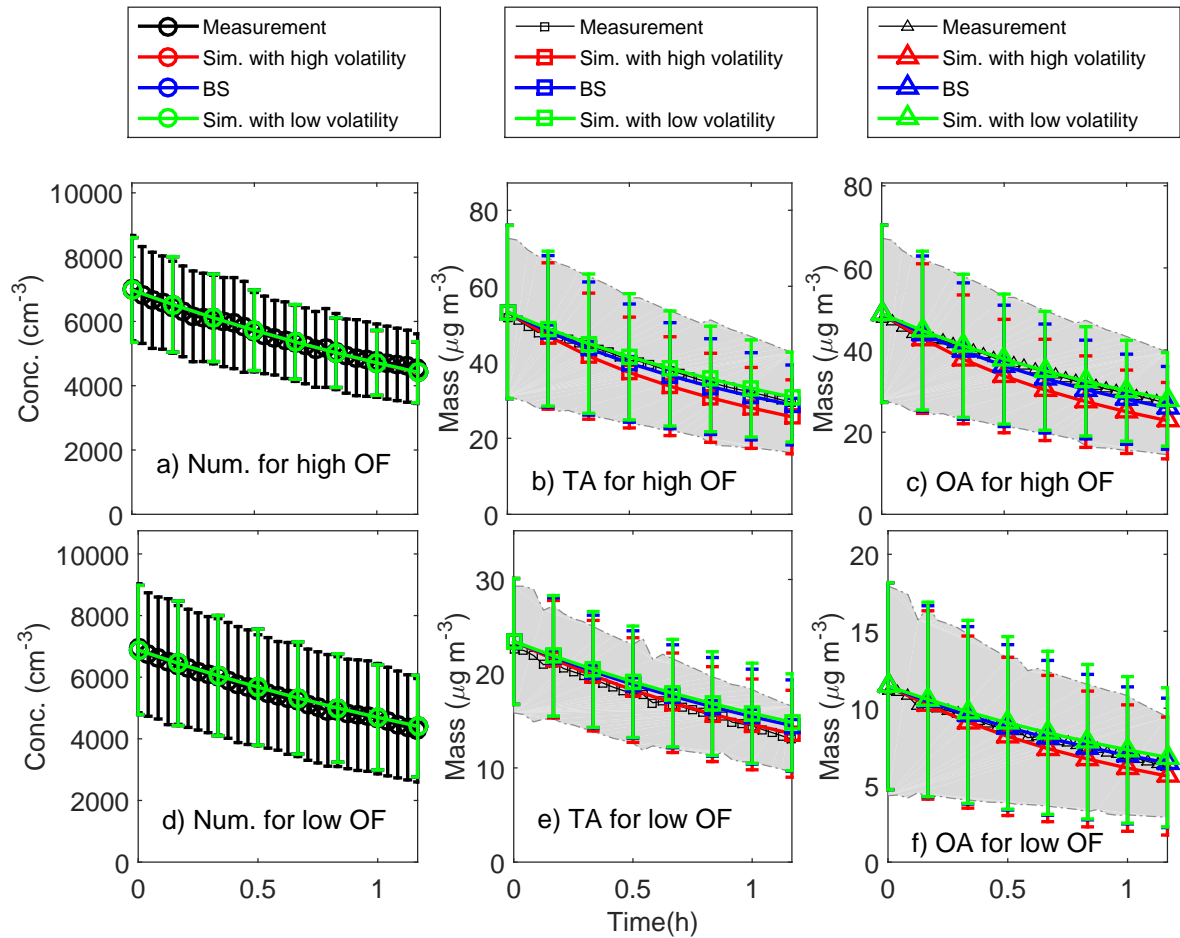

c) OA for high OF

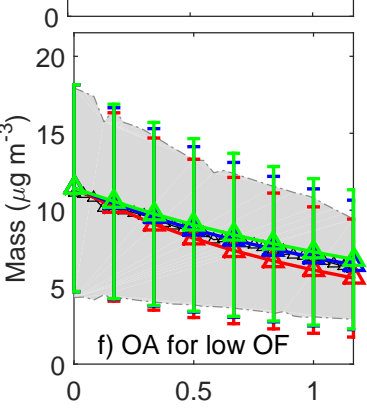

Figure 5. Similar to Fig. 2 but comparing simulations with bounding initial volatilities derived from May et al. (2013b).

bound distribution of May et al. (2013b) better estimates the high-OF experiments while the best-fit distribution provides the best results for the low-OF experiments (with all other parameters set to their base values). The final TA in highvolatility simulations matches the measurements better than the other volatility assumptions for the low-OF experiments; however, as discussed earlier the final measured TA in the lower-OF experiments is likely biased high, and this is compensated by the bias caused by the higher volatility distribution. Figure 6 shows the decrease in particle and vapor organics throughout the simulations. The lower-bound volatility distribution simulations had more particle-phase organics with lower volatilities, which caused a decrease of $29 \%$ in the particle-phase organic mass loss by evaporation, relative to the base-case simulations. Conversely, the upper-bound volatility distribution simulations have $18 \%$ more particlephase organic mass lost relative to the base-assumption simulations ( $48 \%$ lost rather than $41 \%$ ), due to more evaporation. While the relative importance of particle-phase wall loss versus vapor-phase wall loss followed by particle evaporation for determining total accumulated particle-organic mass loss shifts somewhat depending on the volatility distribution, both pathways of particle-phase organic mass loss have non-trivial contributions regardless of the assumed volatility distribution (Fig. 6). In addition, as mentioned before, since May et al. (2013b) did not consider vapor wall loss when deriving the volatility distribution, our calculations may underestimate the importance of vapor wall losses and the uncer- tainty attributable to the uncertainty in the volatility distribution may be larger than $18 \%$.

\subsubsection{Effect of $C_{\mathrm{w}} / M_{\mathrm{w}} \gamma_{\mathrm{w}}$}

$C_{\mathrm{w}} / M_{\mathrm{w}} \gamma_{\mathrm{w}}$, the parameters describing the saturation concentration of the vapor with respect to the wall, was measured to be $9,20,50$ and $120 \mu$ mole $\mathrm{m}^{-3}$ for different organic species in Matsunaga and Ziemann (2010). Varying $C_{\mathrm{w}} / M_{\mathrm{w}} \gamma_{\mathrm{w}}$ over this range has no significant change on the simulation (Fig. 7). The simulation using the lower bound of $C_{\mathrm{w}} / M_{\mathrm{w}} \gamma_{\mathrm{w}}\left(9 \mu\right.$ mole $\left.^{-3}\right)$ causes a $26 \%$ lower total amount of vapor to be lost to the wall compared with the higher bound (Fig. 8), because $k_{\mathrm{w}, \text { off }}$ values are $\sim 1$ order of magnitude faster under the $9 \mu$ mole $\mathrm{m}^{-3}$ assumption (Table 3 ). Even though the net vapor loss is slowed somewhat, the mean particle-organic mass remaining at the end of the experiments is not significantly different $(<0.9 \%$ increase) from the $120 \mu$ mole $\mathrm{m}^{-3}$ assumption. In the study of Zhang et al. (2015), $C_{\mathrm{w}}$ was found to be highly dependent on the volatility and solubility in Teflon polymer. Use of adapted varying $C_{\mathrm{w}} / M_{\mathrm{w}} \gamma_{\mathrm{w}}$ values (Table 3 ) in our model shows a high bias in the final predicted OA $(6.3 \%$ for high-OF experiments and $7.6 \%$ for low-OF experiments) and a decrease of $65 \%$ in the net vapor loss relative to the base-assumption simulation. The contribution of the evaporative OA lost to the wall also decreases from 35 to $21 \%$ of the total OA loss. These findings resulted because the adapted $C_{\mathrm{w}} / M_{\mathrm{w}} \gamma_{\mathrm{w}}$ 


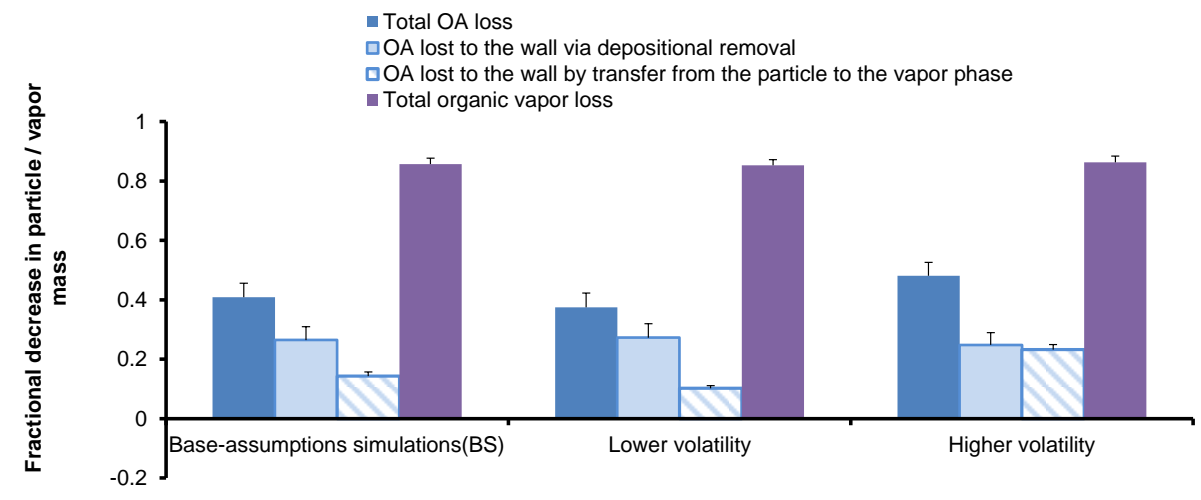

Figure 6. The organic species mass budgets for the base-assumption simulations and two sensitivity studies using bounding volatility distributions. All other variables as in Fig. 3b.

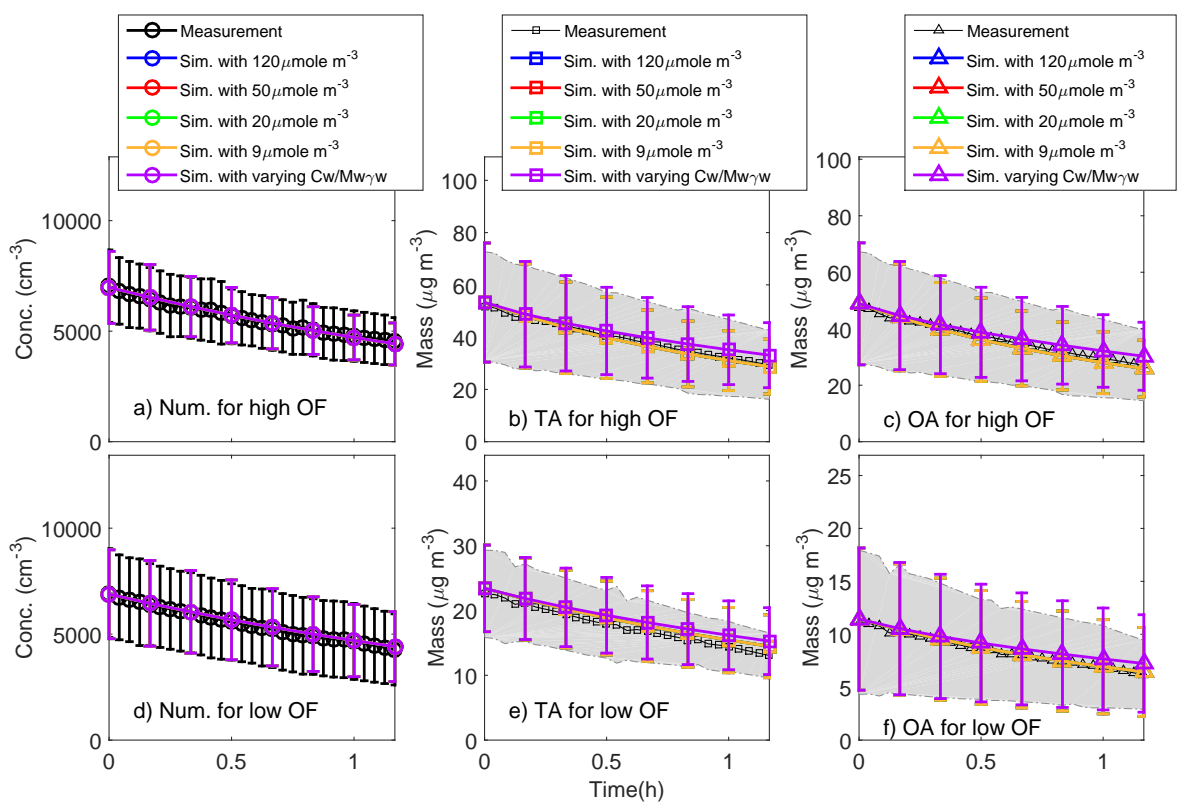

Figure 7. Similar to Fig. 2 except using different $C_{\mathrm{w}} / M_{\mathrm{w}} \gamma_{\mathrm{w}}$ of 120 (base-assumption simulation), 50, 20, $9 \mu \mathrm{mole} \mathrm{m}^{-3}$ and varying $C_{\mathrm{W}} / M_{\mathrm{w}} \gamma_{\mathrm{w}}$ (adapted from Zhang et al., 2015).

values $\left(1.30 \times 10^{-5}-11.1 \mu\right.$ mole $\mathrm{m}^{-3}$, Table 3$)$ for $C^{*}$ bins from $10^{-3}$ to $10^{4}$ from Zhang et al. (2015) are generally smaller than in the base case $\left(9-120 \mu\right.$ mole m$\left.^{-3}\right)$, which increases $k_{\text {off }}$ and thus lowers the net vapor uptake to the wall. Our simulations demonstrate that $C_{\mathrm{w}}$ or $C_{\mathrm{w}} / M_{\mathrm{w}} \gamma_{\mathrm{w}}$ is an important parameter in the model, especially for vapor wall-loss estimation, and use of $C_{\mathrm{w}} / M_{\mathrm{w}} \gamma_{\mathrm{w}}$ in the range of 9-120 $\mu$ mole $\mathrm{m}^{-3}$ captures the OA evolution in the woodsmoke chamber (when other parameters are set to their base assumptions), although this range of $C_{\mathrm{w}} / M_{\mathrm{w}} \gamma_{\mathrm{w}}$ was measured for relatively higher volatility organic species (e.g. nalkane, $\mathrm{C}_{5}-\mathrm{C}_{16}$ with $C^{*}$ bins of $10^{5}-10^{9} \mu \mathrm{g} \mathrm{m}^{-3}$, exceeding our simulated volatility range) and it may not be appropriate to use a single value for all $C^{*}$ bins. To improve the model simulation and reduce the uncertainty in vapor loss estimation, more work is needed to develop accurate $C_{\mathrm{w}}$ or $C_{\mathrm{w}} / M_{\mathrm{w}} \gamma_{\mathrm{w}}$ values for organic species present in wood smoke and relevant to the chamber materials used in SOA experiments.

\subsubsection{Effect of accommodation coefficients for vapor with the wall and particles}

In our base-assumption simulations, particle mass is lost in similar amounts via particle deposition and via evaporation (driven by vapor wall losses). This result suggests that assumptions regarding the accommodation coefficients for condensation onto the wall and/or onto particles $\left(\alpha_{\mathrm{w}}, \alpha_{\mathrm{p}}\right)$, may influence the particle-organic mass loss via evaporation. Figures 9, 10 and 11 show how modifying the accommoda- 


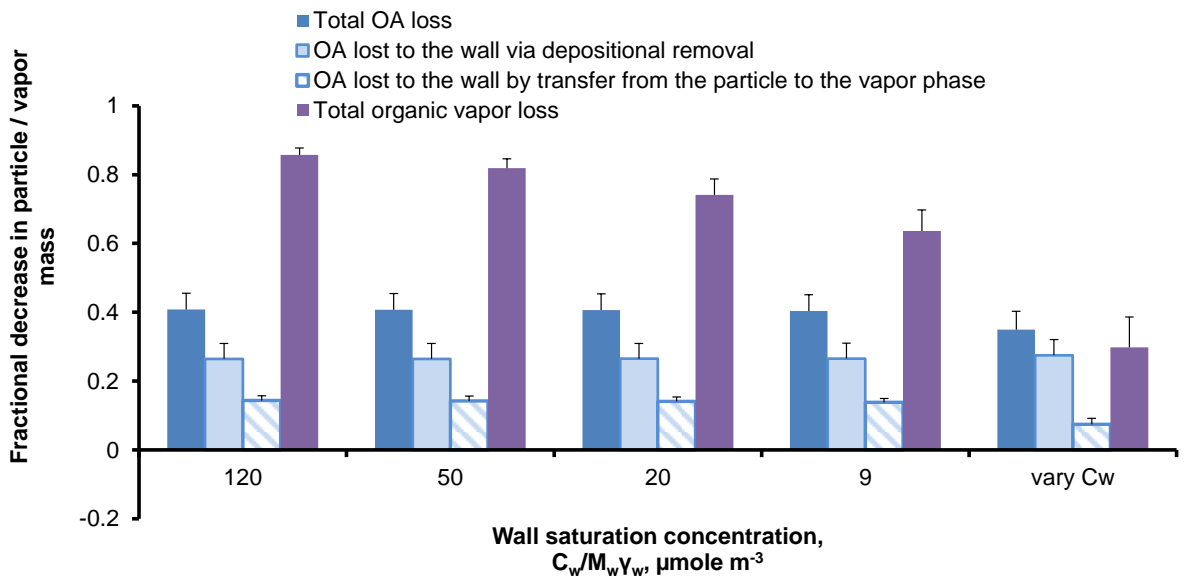

Figure 8. The organic species mass budgets for the base-assumption simulations $\left(C_{\mathrm{w}} / M_{\mathrm{w}} \gamma_{\mathrm{w}}\right.$ of $\left.120 \mu \mathrm{mole}^{-3}\right)$ and three other sensitivity simulations using lower wall saturation concentration $\left(C_{\mathrm{w}} / M_{\mathrm{w}} \gamma_{\mathrm{w}}\right.$ of 50,20 and $9 \mu$ mole $\left.\mathrm{m}^{-3}\right)$ and varying $C_{\mathrm{w}} / M_{\mathrm{w}} \gamma_{\mathrm{w}}($ adapted from Zhang et al., 2015). All other variables as in Fig. $3 b$.

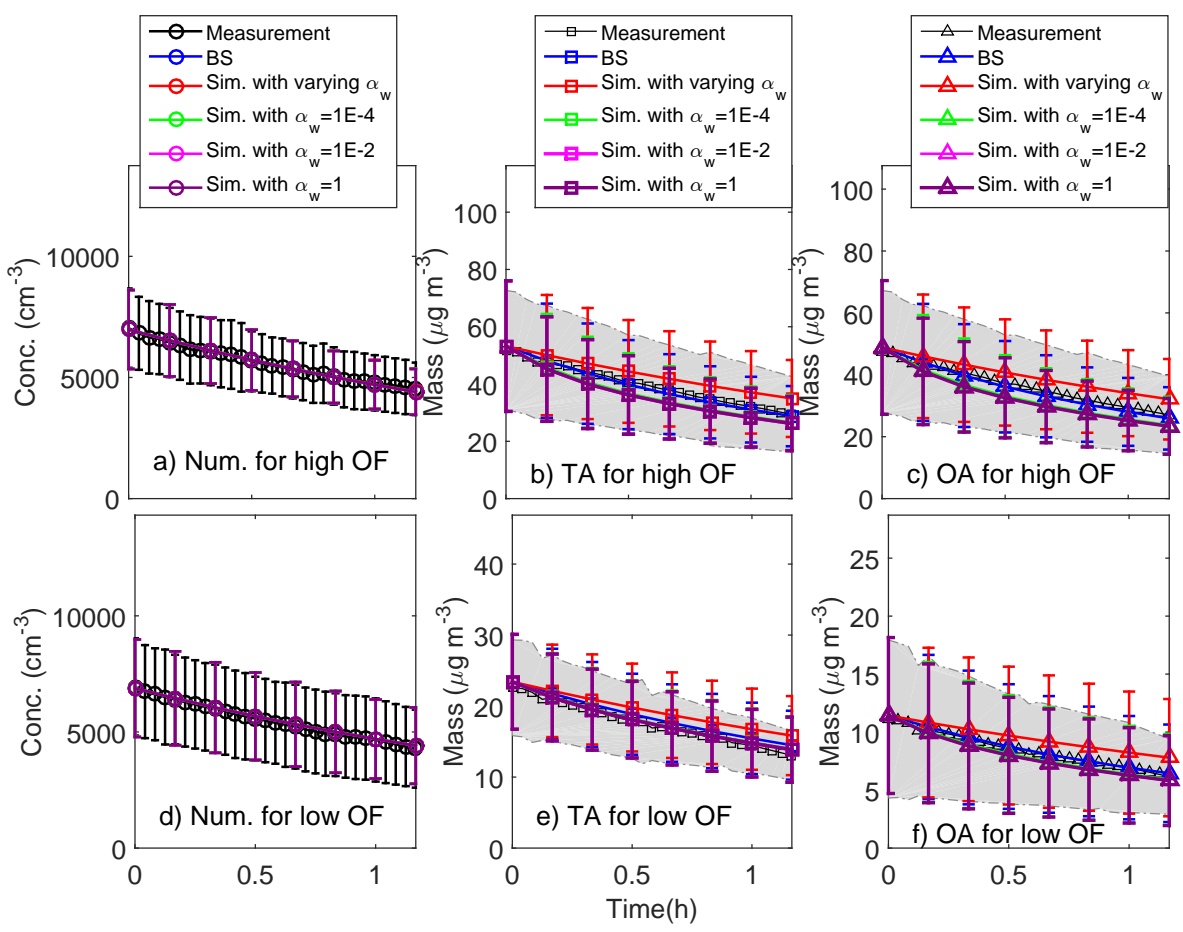

Figure 9. Similar to Fig. 2 except for the simulations with different accommodation coefficients of vapor with walls, $\alpha_{\mathrm{W}}$, computed as a function of $C_{i}^{*}$ (Zhang et al., 2015) and taking the values of $1 \times 10^{-4}, 1 \times 10^{-2}$ and 1 .

tion coefficients alter our simulations. In our base simulation, we assumed values of $10^{-5}$ and 1 for $\alpha_{\mathrm{w}}$ and $\alpha_{\mathrm{p}}$, respectively as used in Matsunaga and Ziemann (2010) and May et al. (2013b). To test the effects of uncertainty in $\alpha_{\mathrm{w}}$, we perform sensitivity studies where (1) $\alpha_{\mathrm{w}}$ is calculated as a function of $C_{i}^{*}$ with a range from $10^{-8}$ to $10^{-6}$ as proposed by Zhang et al. (2015) and shown in Table 3, and (2) $\alpha_{\mathrm{w}}$ is set to a constant value of $10^{-4}, 10^{-2}$, and 1 , respectively, and $\alpha_{\mathrm{p}}$ is set to unity. Figure 11 shows that applying the lower $\alpha_{\mathrm{w}}$ as a function of $C_{i}^{*}$, from Zhang et al. (2015) causes only a $3.9 \%$ decrease in vapor-organics concentrations, and the vapor evaporation from particles is almost entirely suppressed because $k_{\mathrm{w}, o n}$ for $C_{i}^{*}$ dependent $\alpha_{\mathrm{w}}$ is several orders of magnitude lower than in the base-assumption simulation $\left(\alpha_{\mathrm{w}}\right.$ of $10^{-5}$, Table 3 ) and thus leads to negligible vapor wall loss on the $1 \mathrm{~h}$ experimental timescale, compared with more substantial particle wall losses. These results are very similar to our simulations with no vapor loss, and thus they lead to a high 


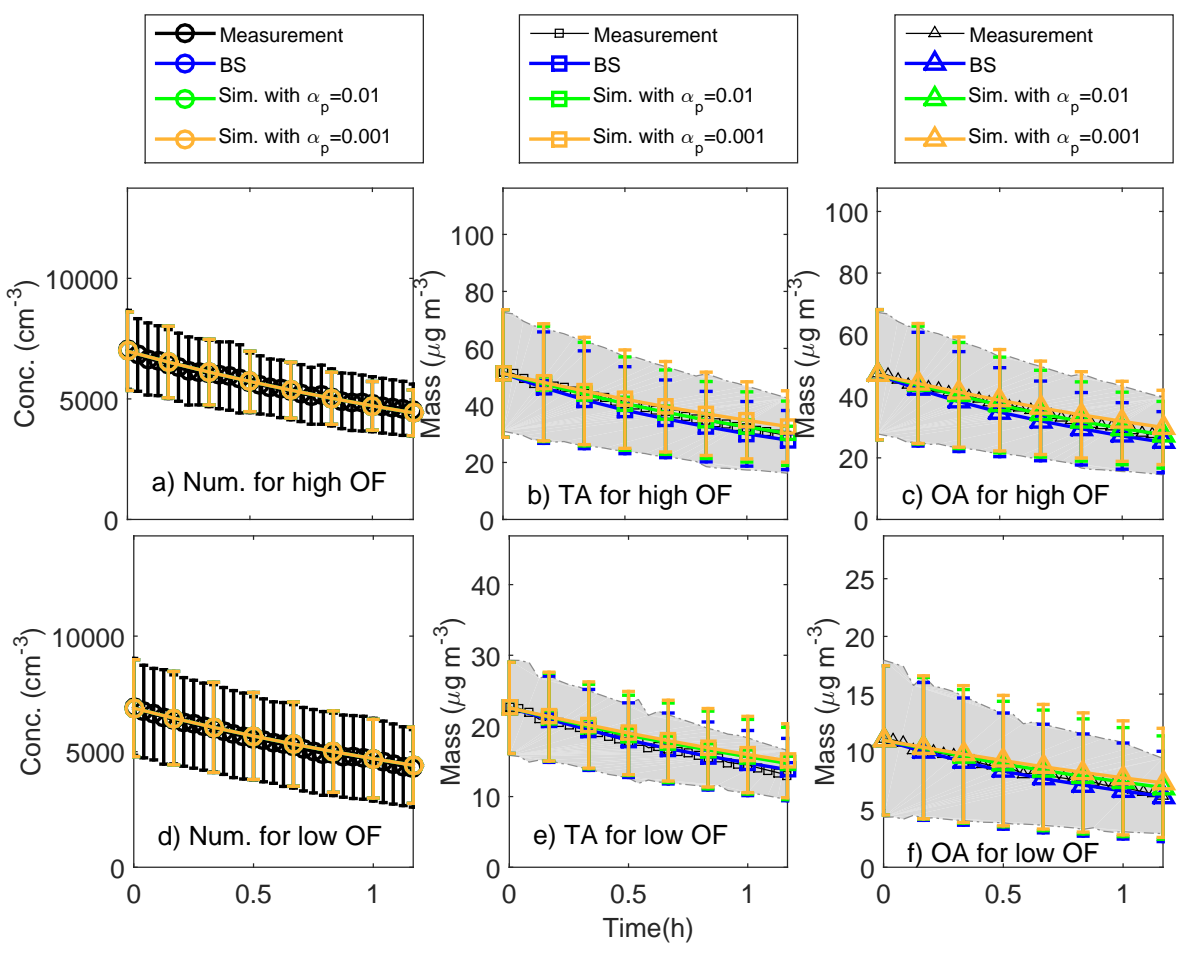

Figure 10. Similar to Fig. 2 except for the simulations with different accommodation coefficients of vapor with particles $\left(\alpha_{\mathrm{p}}\right)$ of 0.01 and 0.001 .

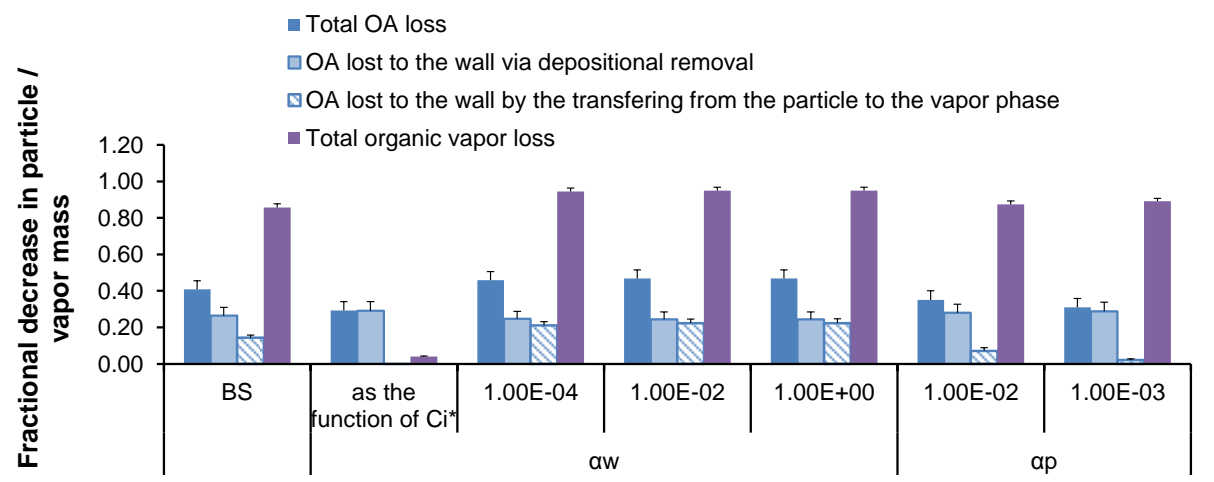

Figure 11. The organic species mass budgets for the base-assumption simulations (accommodation coefficient of vapor with wall $\left(\alpha_{\mathrm{w}}\right)$ of $1 \times 10^{-5}$ and accommodation coefficient of vapor with particle $\left(\alpha_{\mathrm{p}}\right)$ of 1 and the sensitivity studies on $\alpha_{\mathrm{w}} \alpha$ as the function of $C_{i}^{*}$ and of the values $1 \times 10^{-4}, 1 \times 10^{-2}$, and 1 ) and $\alpha_{\mathrm{p}}$ (of 0.01 and 0.001 ). All other variables as in Fig. $3 \mathrm{~b}$.

bias in final OA (12 and $14 \%$ for high- and low-OF simulations, Table 5) relative to the measurements, showing that these lower $\alpha_{\mathrm{w}}$ values may be unrealistic. For the simulations using higher $\alpha_{\mathrm{w}}\left(10^{-4}, 10^{-2}\right.$, and 1), we find when $\alpha_{\mathrm{w}}$ increases above $1 \times 10^{-4}$, accommodation of vapors to the wall no longer limits the vapor wall-loss rate and exerts limited influence on OA loss, as shown in Fig. 11. The total OA loss increases from 41 to $47 \%$ of initial particle-phase organic mass if $\alpha_{\mathrm{w}}$ increases from $10^{-5}$ to $10^{-4}$, causing a lower bias in the final OA ( -14 and $-9.5 \%$ for high- and low-OF simulations, Table 5). The proportion of OA wall loss via particle wall loss versus particle evaporation changes from $65: 35 \%$ to $52: 48 \%$, due to increased vapor wall losses. In summary, $\alpha_{\mathrm{w}}$ is an important factor in our calculations although its effect saturates for $\alpha_{\mathrm{w}}$ larger than $10^{-4}$.

We also test non-unity values of $\alpha_{\mathrm{p}}(0.01$ and 0.001$)$. While these non-unity $\alpha_{\mathrm{p}}$ values have been suggested for both biogenic and anthropogenic SOA studies (Zhang et al., 2014; McVay et al., 2014), it is not clear if these values are applicable to primary wood-smoke aerosol. $\alpha_{\mathrm{p}}$ of 0.01 and 0.001 decreases the particle-organic mass loss by evaporation by 51 and $85 \%$ of the base-assumption simulations, re- 


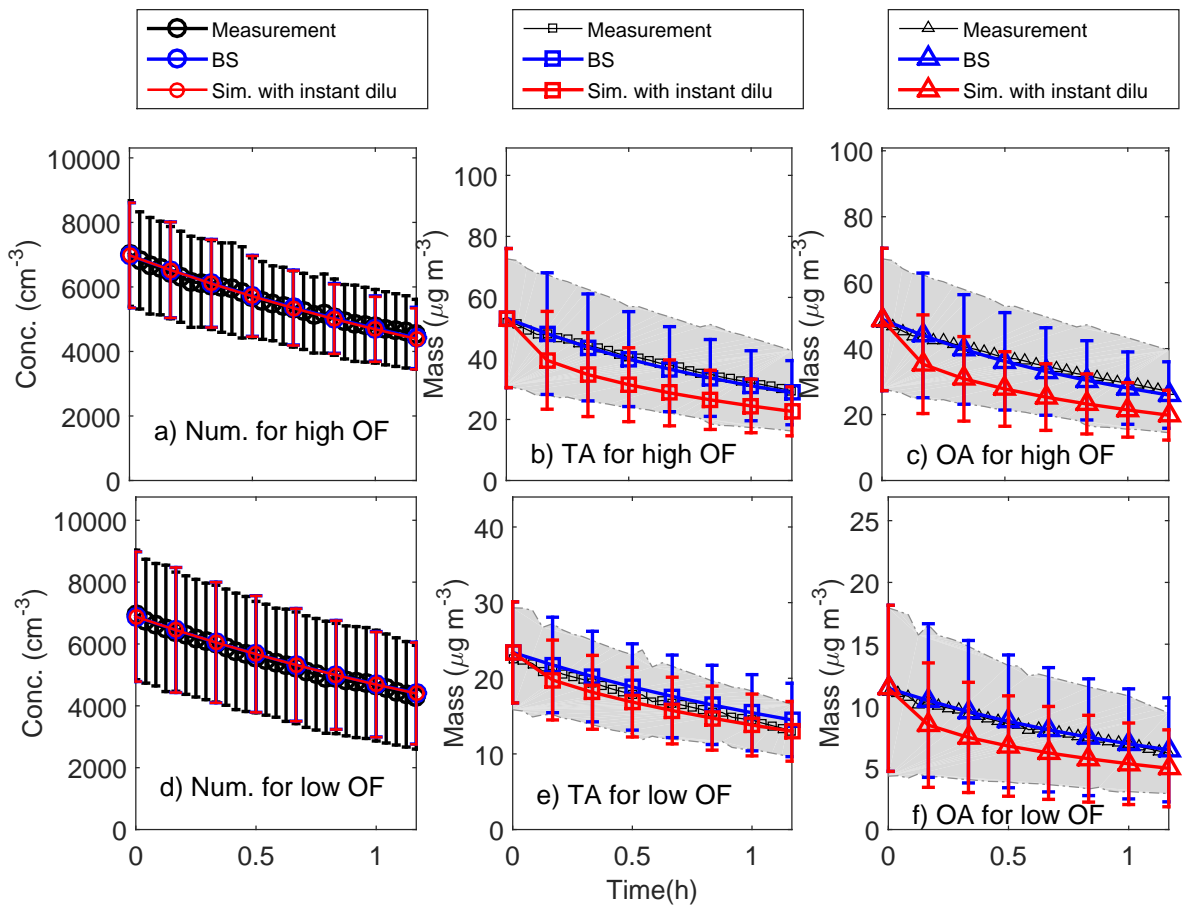

Figure 12. Similar to Fig. 2 but for the simulation with instantaneous dilution by $25: 1$.

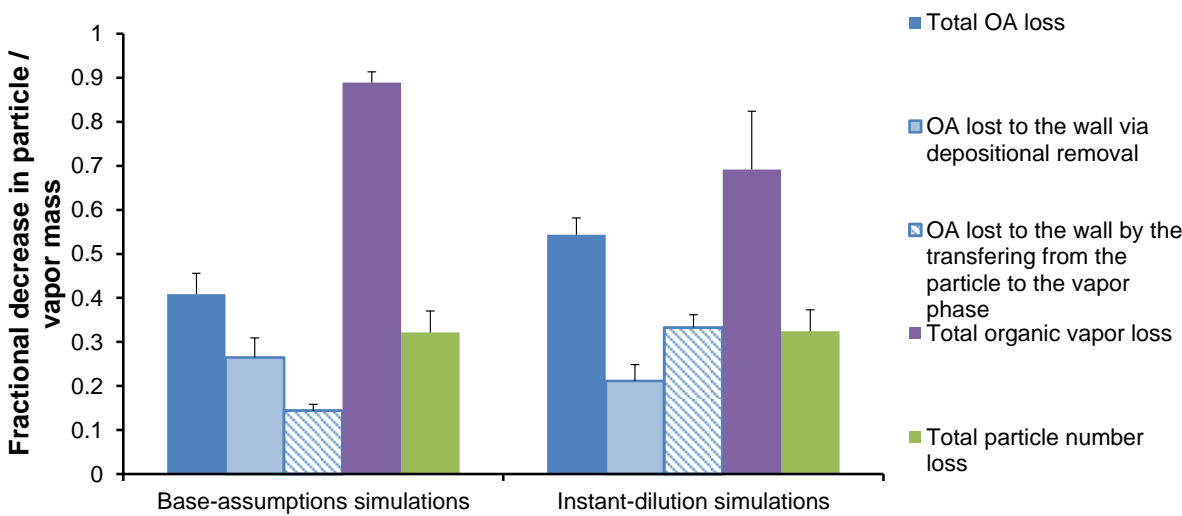

Figure 13. The organic species mass budgets and total number net loss for the base-assumption simulations and instant-dilution simulations. See Fig. $3 b$ for a full description.

spectively, (Fig. 11) because the reduced $\alpha_{\mathrm{p}}$ increases the timescale for particle evaporation and less vapor is consequently transferred to the gas-phase. As a result, the final OA concentrations are biased high by 0.44 and $8.3 \%$ for $\alpha_{p}$ of 0.01 and 0.001 for the high-OF simulations and by 6.3 and $12 \%$ for the low-OF simulations (Table 5), which shows that $\alpha_{\mathrm{p}}$ of 0.01 may be still applicable to our study but $\alpha_{\mathrm{p}}$ of 0.001 may be less likely than our base assumption of unity. Thus, changing the accommodation coefficients may significantly alter the particle mass loss by increasing the evaporation timescales; however, the changes in the accommodation coefficients from our base values may worsen the compar- isons to measurements (Figs. 9 and 10), depending on the combination of other parameters used in the model.

\subsubsection{Effect of the dilution}

In our base case simulations, we assume that the particles and vapors are in equilibrium at the time when the measurements started in the smog chamber. As discussed earlier, in the FLAME III experiments, the POA was diluted by $\sim 25: 1$ as it was moved from the burn chamber to the smog chamber. Thus, it is possible that the vapor and particles were not in equilibrium at the start of the measurements. To test the sensitivity of our findings to the assumption that the particles and 
vapor were in equilibrium at the start of the measurements, we perform alternate simulations where we assume that the particles and vapor are in equilibrium prior to dilution, and the smog chamber is filled instantly with the simulation starting at this point, and thus the particles and vapor are out of equilibrium at the start of the simulation. Note that the initial total particle concentrations are still the same; however, the vapor concentrations and particle composition have changed compared to the start of the base case. As discussed earlier, it is not clear if these instant-dilution simulations are a better assumption than our base assumption of initial equilibrium because the CMU chambers were filled by the diluted air gradually over $30 \mathrm{~min}$, and thus the system would have some time to equilibrate (and/or for particles and vapors to be lost to the walls) before the experiment started. However, we treat the instant-dilution assumption as a bounding sensitivity test to our initial-equilibrium assumption.

Figures 11 and 12 show the results of these simulations. The dilution of gas and aerosol by 25 times in the smog chamber drives the particles to evaporate. The dilution exerts no significant influence on the number loss (Figs. 12 and 13). The particle-organic mass lost to the walls increases by $33 \%$ relative to our base-assumption simulations due to the additional evaporation from particles caused by dilution into clean air. Particle-phase wall loss decreased by $20 \%$ and mass loss as vapor increased by $131 \%$ in instantaneous dilution simulation compared with the base simulation (Fig. 13). Thus, whether the particles reach equilibrium after dilution into the smog chamber is an important consideration. However, the instant dilution causes OA losses to be significantly larger than the observed decreases (Fig. 12); thus this assumption is likely unrealistic for these experiments with slow dilution. On the other hand, considering that some sensitivity simulations for the accommodation coefficients $\left(\alpha_{\mathrm{p}}\right.$ and $\left.\alpha_{\mathrm{w}}\right)$ and wall saturation coefficients $\left(C_{\mathrm{w}} / M_{\mathrm{w}} \gamma_{\mathrm{w}}\right)$ showed hindered evaporation relative to the base assumptions, it is possible that the evaporation driven by dilution is dampened by lower accommodation coefficients (not shown). Thus, while our base assumptions provided the best comparison to the measurements of the simulations tested, it is plausible that some combination of parameters may also provide simulation results that match the measurements.

\subsubsection{Discussion on potential SOA-formation effects}

The study of SOA formation in FLAME III was performed for 3-4.5 h after POA measurement by turning on UV light or sunlight (Hennigan et al., 2011). The light was turned on after the particles had typically been in the chamber for $\sim 75 \mathrm{~min}$. SOA is usually formed from the oxidation of the gaseous semi-volatile or intermediate-volatility species (Nakao et al., 2011; Yee et al., 2013). During the period prior to photo-oxidation, the concentrations of these vapors may drop by over $90 \%$ within an hour under our base assumption (Fig. 3b). Thus, vapor wall loss may have signifi- cant influence on SOA production. In addition, SOA is subject to the same particle- and vapor-phase loss mechanisms as is POA during the experiments. However, due to the reversible nature of vapors on the wall, vapors may be released from the wall if significant precursor vapors are consumed by photo-oxidation. To properly estimate the SOA production in wood-smoke plumes in the atmosphere, one must correct the fraction of precursor vapors in the smoke that were lost to the wall and not available for photo-oxidation, and thus the uncorrected estimates of SOA production in Hennigan et al. (2011) may be an underestimate. In this work, we only simulated species with saturation concentrations $10^{4} \mu \mathrm{g} \mathrm{m}^{-3}$ and lower, while precursor vapors may also be at higher saturation concentrations. Given the relationships between saturation concentration and wall uptake that we use in the sensitivity test (Zhang et al., 2015), higher volatility vapors may not be lost to the walls as efficiently as those in the volatility range tested here. To perform the wall-loss correction for wood-smoke SOA, we must also know which vapors (or which volatility bins) contain the precursors for SOA formation, and thus we leave the losses of these higher volatility vapors and the simulation of SOA formation for future work.

\section{Conclusions}

We systematically investigate particle and vapor wall losses in controlled wood-smoke smog-chamber experiments. The semi-volatile nature of biomass-burning primary organic aerosol means that both particles and vapors may be lost to Teflon smog chamber walls. Vapor loss to the walls may lead to evaporation of the particles, and may lead to a reduction in the concentration of SOA precursors in the wood-smoke experiments.

We use the TOMAS microphysics box model coupled with particle and vapor wall-loss formulations to estimate particle and vapor wall loss in 18 wood-smoke smog-chamber experiments. The TOMAS model generally captures the number and mass loss (SMPS and AMS data) across the 18 woodsmoke chamber experiments under our base assumptions for several uncertain parameters. The percent bias between average base-assumption simulations and measurements after $1 \mathrm{~h}$ of evolution is $-1.4,3.1$ and $-4.8 \%$ for number, TA (total aerosol) and OA (organic aerosol), respectively, for the high-OF (organic fraction) experiments and 0.94, 6.6 and $0.12 \%$ for the low-OF experiments. The percent bias between the standard deviations of these base-assumption simulations and measurements is 11,22 and $21 \%$ for number, TA and OA, respectively, for the high-OF experiments and $4.9,31$ and $15 \%$ for the low-OF experiments. Under the simulations with our best-guess parameters, the model estimates that the particle-organic mass loss by direct particle wall loss and organic evaporation driven by vapor wall loss are roughly equally important contributing 65 and $35 \%$ of the total loss (average across the 18 experiments), respectively. The vapor 
concentration drops by $86 \%$ of its initial value due to vapor wall loss. As a result, the volatility distribution of the remaining mass in the chamber shifts to lower volatilities by the end of the experiment.

We conducted sensitivity tests by parameter perturbation to explore uncertainties in several model inputs: the volatility distribution, the effect of assumed saturation concentrations for the wall $\left(C_{\mathrm{w}} / M_{\mathrm{w}} \gamma_{\mathrm{w}}\right)$, and the accommodation coefficients of the vapor-phase organics with particles $\left(\alpha_{\mathrm{p}}\right)$ and the wall $\left(\alpha_{\mathrm{w}}\right)$. The model uncertainties of final OA concentration estimated using volatility distribution bounds provided in May et al. (2013) is $~ 18 \%$ of the value relative to the base assumption simulations. The total organic mass loss is generally insensitive to $C_{\mathrm{w}} / M_{\mathrm{w}} \gamma_{\mathrm{w}}$ for the range of values provided by Matsunaga and Ziemann (2010) (i.e. 9-120 $\mu$ mole $\mathrm{m}^{-3}$ ), but the vapor uptake to the walls and evaporation of particles is greatly dampened if the volatility dependent values suggested by Zhang et al. (2015) are used. $\alpha_{\mathrm{p}}$ and $\alpha_{\mathrm{w}}$ are demonstrated to be important parameters in the model simulation. Comparison between measurements and our simulations suggests that $\alpha_{\mathrm{w}}$ of $10^{-5}$ and $\alpha_{\mathrm{p}}$ of 1 or 0.01 are applicable in our wood-smoke chamber simulations when other parameters were set to their base assumptions. Finally, the dilution between the source aerosol and the smog chamber can cause an increase of $33 \%$ in the total particulate organic mass loss to the chamber walls, due to an increase in organic particle evaporation driven by the dilution into clean air.

While our base assumptions of the uncertain parameters provided the best comparison to measurements in the simulations tested here, it is plausible that another combination of parameters (e.g. vapors initially sub-saturated with lower accommodation coefficients) may also provide agreement with the measurements. Unfortunately, without direct measurements of the semi-volatile vapors it is not possible to entirely constrain the loss processes in the chamber, so we are left to test values suggested in previous work.

As SOA from wood smoke is suspected to be formed from photo-oxidation of semi-volatile and/or intermediatevolatility species, our studies indicate that most of the SOA precursor vapors may be lost to the smog chamber walls during controlled wood-smoke SOA experiments. These vapor losses could cause a potentially large underestimation of the SOA that may be produced in the atmosphere from oxidation of wood-smoke emissions. However, further investigation as to how wall losses affect SOA production in smog-chamber studies awaits new data on the identities and volatilities of the key precursor species.

The Supplement related to this article is available online at doi:10.5194/acp-15-11027-2015-supplement.
Acknowledgements. This study was supported by the Joint Fire Science Program (JFSP) under project 14-1-03-26. We thank the Fire Lab At Missoula Experiment (FLAME) III project team and Cyle Wold, Emily Lincoln, and Wei Min Hao from the FSL for their support in organizing and conducting the FLAME-III study and for providing the data set used here. Funding for the FLAME-III project was provided by the National Park Service, JFSP and the EPA STAR program through the National Center for Environmental Research (NCER) under grants R833747 and R834554, and DOE (BER, ASR program) DE-SC0006035.

Edited by: K. Lehtinen

\section{References}

Abramowitz, M. and Stegun, I.: Handbook of Mathematical Functions: With Formulas, Graphs, and Mathematical Tables, Courier Corporation, Dover, New York, 1964.

Adams, P. J. and Seinfeld, J. H.: Predicting global aerosol size distributions in general circulation models, J. Geophys. Res., 107, 4370, doi:10.1029/2001JD001010, 2002.

Akagi, S. K., Craven, J. S., Taylor, J. W., McMeeking, G. R., Yokelson, R. J., Burling, I. R., Urbanski, S. P., Wold, C. E., Seinfeld, J. H., Coe, H., Alvarado, M. J., and Weise, D. R.: Evolution of trace gases and particles emitted by a chaparral fire in California, Atmos. Chem. Phys., 12, 1397-1421, doi:10.5194/acp-121397-2012, 2012.

Bond, T. C., Doherty, S. J., Fahey, D. W., Forster, P. M., Berntsen, T., DeAngelo, B. J., Flanner, M. G., Ghan, S., Kärcher, B., Koch, D., Kinne, S., Kondo, Y., Quinn, P. K., Sarofim, M. C., Schultz, M. G., Schulz, M., Venkataraman, C., Zhang, H., Zhang, S., Bellouin, N., Guttikunda, S. K., Hopke, P. K., Jacobson, M. Z., Kaiser, J. W., Klimont, Z., Lohmann, U., Schwarz, J. P., Shindell, D., Storelvmo, T., Warren, S. G., and Zender, C. S.: Bounding the role of black carbon in the climate system: a scientific assessment, J. Geophys. Res. Atmos., 118, 5380-5552, doi:10.1002/jgrd.50171, 2013.

Capes, G., Murphy, J. G., Reeves, C. E., McQuaid, J. B., Hamilton, J. F., Hopkins, J. R., Crosier, J., Williams, P. I., and Coe, H.: Secondary organic aerosol from biogenic VOCs over West Africa during AMMA, Atmos. Chem. Phys., 9, 3841-3850, doi:10.5194/acp-9-3841-2009, 2009.

Chung, C. E., Ramanathan, V., and Decremer, D.: Observationally constrained estimates of carbonaceous aerosol radiative forcing, P. Natl. Acad. Sci. USA, 109, 11624-11629, doi:10.1073/pnas.1203707109, 2012.

Crump, J. G. and Seinfeld, J. H.: Turbulent deposition and gravitational sedimentation of an aerosol in a vessel of arbitrary shape, J. Aerosol Sci., 12, 405-415, 1981.

Cubison, M. J., Ortega, A. M., Hayes, P. L., Farmer, D. K., Day, D., Lechner, M. J., Brune, W. H., Apel, E., Diskin, G. S., Fisher, J. A., Fuelberg, H. E., Hecobian, A., Knapp, D. J., Mikoviny, T., Riemer, D., Sachse, G. W., Sessions, W., Weber, R. J., Weinheimer, A. J., Wisthaler, A., and Jimenez, J. L.: Effects of aging on organic aerosol from open biomass burning smoke in aircraft and laboratory studies, Atmos. Chem. Phys., 11, 12049-12064, doi:10.5194/acp-11-12049-2011, 2011. 
DeCarlo, P. F., Slowik, J. G., Worsnop, D. R., Davidovits, P., and Jimenez, J. L.: Particle morphology and density characterization by combined mobility and aerodynamic diameter measurements. Part 1: Theory, Aerosol Sci. Tech., 38, 1185-1205, doi:10.1080/027868290903907, 2004.

DeCarlo, P. F., Ulbrich, I. M., Crounse, J., de Foy, B., Dunlea, E. J., Aiken, A. C., Knapp, D., Weinheimer, A. J., Campos, T., Wennberg, P. O., and Jimenez, J. L.: Investigation of the sources and processing of organic aerosol over the Central Mexican Plateau from aircraft measurements during MILAGRO, Atmos. Chem. Phys., 10, 5257-5280, doi:10.5194/acp-10-52572010, 2010.

Donahue, N. M., Robinson, A. L., Stanier, C. O., and Pandis, S. N.: Coupled partitioning, dilution, and chemical aging of semivolatile organics, Environ. Sci. Technol., 40, 2635-2643, doi:10.1021/es052297c, 2006.

Giordano, M., Espinoza, C., and Asa-Awuku, A.: Experimentally measured morphology of biomass burning aerosol and its impacts on CCN ability, Atmos. Chem. Phys., 15, 1807-1821, doi:10.5194/acp-15-1807-2015, 2015.

Grieshop, A. P., Donahue, N. M., and Robinson, A. L.: Is the gas-particle partitioning in alpha-pinene secondary organic aerosol reversible?, Geophys. Res. Lett., 34, L14810, doi:10.1029/2007GL029987, 2007.

Grieshop, A. P., Miracolo, M. A., Donahue, N. M., and Robinson, A. L.: Constraining the volatility distribution and gasparticle partitioning of combustion aerosols using isothermal dilution and thermodenuder measurements, Environ. Sci. Technol., 43, 4750-4756, doi:10.1021/es8032378, 2009.

Hennigan, C. J., Miracolo, M. A., Engelhart, G. J., May, A. A., Presto, A. A., Lee, T., Sullivan, A. P., McMeeking, G. R., Coe, H., Wold, C. E., Hao, W.-M., Gilman, J. B., Kuster, W. C., de Gouw, J., Schichtel, B. A., Collett Jr., J. L., Kreidenweis, S. M., and Robinson, A. L.: Chemical and physical transformations of organic aerosol from the photo-oxidation of open biomass burning emissions in an environmental chamber, Atmos. Chem. Phys., 11, 7669-7686, doi:10.5194/acp-11-76692011, 2011.

Hennigan, C. J., Westervelt, D. M., Riipinen, I., Engelhart, G. J., Lee, T., Collett, J. L., Pandis, S. N., Adams, P. J., and Robinson, A. L.: New particle formation and growth in biomass burning plumes: an important source of cloud condensation nuclei, Geophys. Res. Lett., 39, L09805, doi:10.1029/2012GL050930, 2012.

Huffman, J. A., Docherty, K. S., Mohr, C., Cubison, M. J., Ulbrich, I. M., Ziemann, P. J., Onasch, T. B., and Jimenez, J. L.: Chemically-resolved volatility measurements of organic aerosol from different sources, Environ. Sci. Technol., 43, 5351-5357, doi:10.1021/es803539d, 2009.

Jacobson, M. Z.: Effects of biomass burning on climate, accounting for heat and moisture fluxes, black and brown carbon, and cloud absorption effects, J. Gephys. Res.-Atmos., 119, 89809002, doi:10.1002/2014JD021861, 2014.

Jassen, N. A. H., Gerlofs-Nijland, M. E., Lanki, T., Salonen, R. O., Cassee, F., Hoek, G., Fischer, P., Brunekreef, B., and Krzyzonowsk, M.: Health Effects of Black Carbon, World Health Organization, Regional Office for Europe, available at: http://www.euro.who.int/_data/assets/pdf_file/0004/ 162535/e96541.pdf (last access: June 2015), 2010.
Jathar, S. H., Gordon, T. D., Hennigan, C. J., Pye, H. O. T., Pouliot, G., Adams, P. J., Donahue, N. M., and Robinson, A. L.: Unspeciated organic emissions from combusition sources and their influence on the secondary organic aerosol budget in the United States, P. Natl. Acad. Sci. USA, 111, 10473-10478, doi:10.1073/pnas.1323740111, 2014.

Jimenez, J. L., Canagaratna, M. R., Donahue, N. M., Prevot, A. S. H., Zhang, Q., Kroll, J. H., DeCarlo, P. F., Allan, J. D., Coe, H., Ng, N. L., Aiken, A. C., Docherty, K. S., Ulbrich, I. M., Grieshop, A. P., Robinson, A. L., Duplissy, J., Smith, J. D., Wilson, K. R., Lanz, V. A., Hueglin, C., Sun, Y. L., Tian, J., Laaksonen, A., Raatikainen, T., Rautiainen, J., Vaattovaara, P., Ehn, M., Kulmala, M., Tomlinson, J. M., Collins, D. R., Cubison, D. R., Dunlea, E. J., Huffman, J. A., Onasch, T. B., Alfarra, M. R., Williams, P. I., Bower, K., Kondo, Y., Schneider, J., Drewnick, F., Borrmann, S., Weimer, S., Demerjian, K., Salcedo, D., Cottrell, L., Griffin, R., Takami, A., Miyoshi, T., Hatakeyama, S., Shimono, A., Sun, J. Y., Zhang, Y. M., Dzepina, K., Kimmel, J. R., Sueper, D., Jayne, J. T., Herndon, S. C., Trimborn, A. M., Williams, L. R., Wood, E. C., Middlebrook, A. M., Kolb, C. E., Baltensperger, U., and Worsnop, D. R.: Evolution of organic aerosols in the atmosphere, Science, 326, 1525-1529, 2009.

Johnston, F. H., Henderson, S. B., Chen, Y., Randerson, J. T., Marlier, M., DeFries, R. S., Kinney, P., Bowman, D. M. J. S., and Brauer, M.: Estimated global mortality attributable to smoke from landscape fires, Environ. Health Persp., 120, 695-701, 2012.

Lee, B., Pierce, J. R., Engelhart, G. J., and Pandis, S. N.: Volatility of secondary organic aerosol from the ozonolysis of monoterpenes, Atmos. Environ., 45, 2443-2452, 2011.

Lipsky, E. M. and Robinson, A. L.: Effects of dilution on fine particle mass and partitioning of semivolatile organics in diesel exhaust and wood smoke, Environ. Sci. Technol., 40, 155-162, doi:10.1021/es050319p, 2006.

Loza, C. L., Chan, A. W. H., Galloway, M., Keutsch, F. N., Flagan, R. C., and Seinfeld, J. H.: Characterization of vapor wall loss in laboratory chambers, Environ. Sci. Technol., 44, 50745078, doi:10.1021/es100727v, 2010.

Matsunaga, A. and Ziemann, P. J.: Gas-wall partitioning of organic compounds in a teflon film chamber and potential effects on reaction product and aerosol yield measurements, Aerosol Sci. Tech., 44, 881-892, doi:10.1080/02786826.2010.501044, 2010.

May, A. A., Presto, A. A., Hennigan, C. J., Nguyen, N. T., Gordon, T. D., and Robinson, A. L.: Gas-particle partitioning of primary organic aerosol emissions: (1) Gasoline vehicle exhaust, Atmos. Environ., 77, 128-139, doi:10.1016/j.atmosenv.2013.04.060, 2013a.

May, A. A., Levin, E. J. T., Hennigan, C. J., Riipinen, I., Lee, T., Collett, J. L., Jimenez, J. L., Kreidenweis, S. M., and Robinson, A. L.: Gas-particle partitioning of primary organic aerosol emissions: 3. Biomass burning, J. Geophys. Res.-Atmos., 118, 11327-11338, doi:10.1002/jgrd.50828, 2013b.

May, A. A., McMeeking, G. R., Lee, T., Taylor, J. W., Craven, J. S., Burling, I., Sullivan, A. P., Akagi, S., Collett Jr., J. L., Flynn, M., Coe, H., Urbanski, S. P., Seinfeld, J. H., Yokelson, R. J., and Kreidenweis, S. M.: Aerosol emissions from prescribed fires in the United States: a synthesis of laboratory and aircraft 
measurements, J. Geophys. Res.-Atmos., 119, 11826-11849, doi:10.1002/2014JD021848, 2014.

May, A. A., Lee, T., McMeeking, G. R., Akagi, S., Sullivan, A. P., Urbanski, S., Yokelson, R. J., and Kreidenweis, S. M.: Observations and analysis of organic aerosol evolution in some prescribed fire smoke plumes, Atmos. Chem. Phys. Discuss., 15, 1953-1988, doi:10.5194/acpd-15-1953-2015, 2015.

McMurry, P. H. and Grosjean, D.: Gas and aerosol wall losses in Teflon film smog chambers, Environ. Sci. Technol., 19, 11761182, doi:10.1021/es00142a006, 1985.

McMurry, P. H. and Rader, D. J.: Aerosol wall losses in electrically charged chambers, Aerosol Sci. Tech., 4, 249-268, doi:10.1080/02786828508959054, 1985.

McVay, R. C., Cappa, C. D., and Seinfeld, J. H.: Vapo-wall deposition in chambers: theoretical considerations, Environ. Sci. Technol., 48, 10251-10258, doi:10.1021/es502170j, 2014.

Naeher, L. P., Brauer, M., Lipsett, M., Zelikoff, J. T., Simpson, C. D., Koenig, J. Q., and Smith, K. R.: Woodsmoke health effects: a review, Inhal. Toxicol., 19, 67-106, 2007.

Nakao, S., Clark, C., Tang, P., Sato, K., and Cocker III, D.: Secondary organic aerosol formation from phenolic compounds in the absence of $\mathrm{NO}_{x}$, Atmos. Chem. Phys., 11, 10649-10660, doi:10.5194/acp-11-10649-2011, 2011.

Ortega, A. M., Day, D. A., Cubison, M. J., Brune, W. H., Bon, D., de Gouw, J. A., and Jimenez, J. L.: Secondary organic aerosol formation and primary organic aerosol oxidation from biomass-burning smoke in a flow reactor during FLAME3, Atmos. Chem. Phys., 13, 11551-11571, doi:10.5194/acp-1311551-2013, 2013.

Pankow, J. F.: An absorption model of gas/particle partitioning of organic compounds in the atmosphere, Atmos. Environ., 28, 185-188, 1994.

Pierce, J. R. and Adams, P. J.: A computationally efficient aerosol nucleation/condensation method: pseudo-steady-state sulfuric acid, Aerosol Sci. Tech., 43, 216-226, 2009.

Pierce, J. R., Engelhart, G. J., Hildebrandt, L., Weitkamp, E. A., Pathak, R. K., Donahue, N. M., Robinson, A. L., Adams, P. J., and Pandis, S. N.: Constraining particle evolution from wall losses, coagulation, and condensation-evaporation in smogchamber experiments: optimal estimation based on size distribution measurements, Aerosol Sci. Tech., 42, 1001-1015, doi:10.1080/02786820802389251, 2008.

Pierce, J. R., Riipinen, I., Kulmala, M., Ehn, M., Petäjä, T., Junninen, H., Worsnop, D. R., and Donahue, N. M.: Quantification of the volatility of secondary organic compounds in ultrafine particles during nucleation events, Atmos. Chem. Phys., 11, 9019 9036, doi:10.5194/acp-11-9019-2011, 2011.

Platt, S. M., El Haddad, I., Zardini, A. A., Clairotte, M., Astorga, C., Wolf, R., Slowik, J. G., Temime-Roussel, B., Marchand, N., Ježek, I., Drinovec, L., Močnik, G., Möhler, O., Richter, R., Barmet, P., Bianchi, F., Baltensperger, U., and Prévôt, A. S. H.: Secondary organic aerosol formation from gasoline vehicle emissions in a new mobile environmental reaction chamber, Atmos. Chem. Phys., 13, 9141-9158, doi:10.5194/acp-13-9141-2013, 2013

Rissler, J., Vestin, A., Swietlicki, E., Fisch, G., Zhou, J., Artaxo, P., and Andreae, M. O.: Size distribution and hygroscopic properties of aerosol particles from dry-season biomass burning in Amazo- nia, Atmos. Chem. Phys., 6, 471-491, doi:10.5194/acp-6-4712006, 2006.

Robinson, A. L., Donahue, N. M., Shrivastava, M. K., Weikamp, E. A., Sage, A. M., Greishop, A. P., Lane, T. E., Pierce, J. R., and Pandis, S. N.: Rethinking organic aerosols: semivolatile emissions and photochemical aging, Science, 315 , 1259-1262, 2007.

Sakamoto, K. M., Allan, J. D., Coe, H., Taylor, J. W., Duck, T. J., and Pierce, J. R.: Aged boreal biomass-burning aerosol size distributions from BORTAS 2011, Atmos. Chem. Phys., 15, 16331646, doi:10.5194/acp-15-1633-2015, 2015.

Saleh, R., Hennigan, C. J., McMeeking, G. R., Chuang, W. K., Robinson, E. S., Coe, H., Donahue, N. M., and Robinson, A. L.: Absorptivity of brown carbon in fresh and photo-chemically aged biomass-burning emissions, Atmos. Chem. Phys., 13, 76837693, doi:10.5194/acp-13-7683-2013, 2013.

Stanier, C. O., Pathak, R. K., and Pandis, S. N.: Measurements of the volatility of aerosols from $\alpha$-pinene ozonolysis, Environ. Sci. Technol., 41, 2756-2763, doi:10.1021/es0519280, 2007.

Vakkari, V., Kerminen, V., Beukes, J. P., Tiitta, P., van Zyl, P. G., Josipovic, M., Venter, A. D., Jaars, K., Worsnop, D. R., Kulmala, M., and Laakso, L.: Rapid changes in biomass burning aerosols by atmospheric oxidation, Geophys. Res. Lett., 41, 2644-2651, doi:10.1002/2014GL059396, 2014.

Weitkamp, E. A., Sage, A. M., Pierce, J. R., Donahue, N. M., and Robinson, A. L.: Organic aerosol formation from photochemical oxidation of diesel exhaust in a smog chamber, Environ. Sci. Technol., 41, 6969-6975, doi:10.1021/es070193r, 2007.

Yee, L. D., Kautzman, K. E., Loza, C. L., Schilling, K. A., Coggon, M. M., Chhabra, P. S., Chan, M. N., Chan, A. W. H., Hersey, S. P., Crounse, J. D., Wennberg, P. O., Flagan, R. C., and Seinfeld, J. H.: Secondary organic aerosol formation from biomass burning intermediates: phenol and methoxyphenols, Atmos. Chem. Phys., 13, 8019-8043, doi:10.5194/acp-13-80192013, 2013.

Yeh, G. K. and Ziemann, P. J.: Alkyl nitrate formation from the reactions of $\mathrm{C}_{8}-\mathrm{C}_{14} \mathrm{n}$-Alkanes with $\mathrm{OH}$ Radicals in the Presence of $\mathrm{NO}_{x}$ : measured yields with essential corrections for gas-wall partitioning, J. Phys. Chem. A., 118, 8147-8157, 2014.

Yokelson, R. J., Crounse, J. D., DeCarlo, P. F., Karl, T., Urbanski, S., Atlas, E., Campos, T., Shinozuka, Y., Kapustin, V., Clarke, A. D., Weinheimer, A., Knapp, D. J., Montzka, D. D., Holloway, J., Weibring, P., Flocke, F., Zheng, W., Toohey, D., Wennberg, P. O., Wiedinmyer, C., Mauldin, L., Fried, A., Richter, D., Walega, J., Jimenez, J. L., Adachi, K., Buseck, P. R., Hall, S. R., and Shetter, R.: Emissions from biomass burning in the Yucatan, Atmos. Chem. Phys., 9, 5785-5812, doi:10.5194/acp-9-5785-2009, 2009.

Zhang, X., Cappa, C. D., Jathar, S. H., McVay, R. C., Ensberg, J. J., Kleeman, M. J., and Seinfeld, J. H.: Influence of vapor wall loss in laboratory chambers on yields of secondary organic aerosol, P. Natl. Acad. Sci. USA, 111, 5802-5807, doi:10.1073/pnas.1404727111, 2014

Zhang, X., Schwantes, R. H., McVay, R. C., Lignell, H., Coggon, M. M., Flagan, R. C., and Seinfeld, J. H.: Vapor wall deposition in Teflon chambers, Atmos. Chem. Phys., 15, 4197-4214, doi:10.5194/acp-15-4197-2015, 2015. 